\title{
Enhanced Heat Transfer of Heat Sink Channels with Micro Pin Fin Roughened Walls
}

\author{
Taiho Yeom ${ }^{\text {a }}$, Terrence Simon ${ }^{\text {a }}$, Tao Zhang ${ }^{\text {a }}$, Min Zhang ${ }^{\text {a }}$ \\ Mark North ${ }^{\mathrm{b}}$, and Tianhong Cui ${ }^{\mathrm{a}, *}$ \\ ${ }^{a}$ Department of Mechanical Engineering, University of Minnesota, Minneapolis, MN 55455, USA \\ ${ }^{\mathrm{b}}$ Thermacore Inc., 780 Eden Road, Lancaster, PA 17601
}

* Corresponding author. Tel: +1 612626 1636; fax: +1 6126256069

E-mail address: cuixx006@me.umn.edu 


\begin{abstract}
Heat transfer and pressure drop characteristics of micro pin fin arrays in a narrow rectangular channel with an air through flow are studied with different flow rates ranging from laminar to turbulent flow. Copper micro pin fins $150 \mu \mathrm{m} \sim 400 \mu \mathrm{m}$ long and $75 \mu \mathrm{m} \sim 700 \mu \mathrm{m}$ in diameter are fabricated by microfabrication techniques. Performance ratios that compare heat transfer to pressure drop characteristics are evaluated to investigate performance of the micro pin-fin surfaces when both heat transfer and pressure drop are important. The results indicates that fluid dynamic effects generated around micro pin fins take a more dominant role for heat transfer enhancement than the area increase due to micro pin fins. A maximum heat transfer enhancement of $79 \%$ over plain surface is achieved due to a micro pin-fin surface with a height of $250 \mu \mathrm{m}$ and a diameter of $400 \mu \mathrm{m}$. It is expected that the micro pin-fin surfaces can be used for improving cooling performance of fan-assisted heat sinks for electronics thermal management.
\end{abstract}

\title{
Keywords
}

Micro pin fins, electronics cooling, heat transfer, channel flow, air flow 


\section{Introduction}

A pin fin array has been a popular method for improving a variety of thermal applications since they increase heat transfer area and enhance convective heat transfer coefficients. Examples of pin fins could be found in cooling turbine airfoils that experience extremely high temperature working conditions. In turbine airfoil cooling, the pin fin array augments convective heat transfer within the internal coolant passages of the airfoils, and provides structural bridges between the two airfoil aerodynamic surfaces [1]. Another traditional application area of pin fin arrays can be found in heat exchanger designs in which a flow is forced through the array of cylinders. Without the benefit of microfabrication, pin fin arrays of earlier studies had relatively large geometric features ranging in size generally over several millimeters in height, diameter, and pitch [1-9]. The key findings of studies on large-scale pin fins mostly agree with each other indicating that a staggered array provides higher heat transfer but induces a larger pressure drop, compared to an in-line array. More recently, the advent of microfabrication technologies allowed shrinking the pin fin structures to the microscale for cooling applications within compact spaces, such as electronics. Moores and Joshi [10] studied the effects of tip clearance over micro pin-fin surfaces with pin fins of $400 \mu \mathrm{m}$ in diameter and different height-to-diameter ratios. The working fluid was water. The pin fin tip clearance was up to $25 \%$ of the pin height. The results showed that heat transfer increased when a small tip clearance is introduced since the pin tips provide more heat transfer area. However, increases of tip clearance resulted in decreasing heat transfer due to bypassing of the flow through the tip clearance region rather than through the bank of pin fins. Marques and Kelly [11] fabricated a micro pin-fin heat exchanger by directly electroplating nickel using the LIGA micro fabrication process. The application was primarily cooling of gas turbine airfoils. The pin fin diameter and height were $500 \mu \mathrm{m}$. Their micro pin-fin structures 
achieved 36\% area increase, and $300 \sim 450 \%$ enhancement in heat transfer with a cross flow of air. Koşar et al. [12] studied hydrodynamic characteristics of micro pin fin arrays in both staggered and in-lined configurations with a flow of de-ionized water. The pin fin height was 100 $\mu \mathrm{m}$ and the two pin fin diameters tested were $50 \mu \mathrm{m}$ and $100 \mu \mathrm{m}$. Reynolds numbers between 5 and 128 were investigated. Their results showed that a staggered array generated higher friction factor values compared to those of an in-lined array of circular pin fins. This trend matched well with previous results for conventional-scale pin fins. Peles et al. [13] derived an analytic expression for the total thermal resistance of a bank of micro pin fins. Their analytical results were experimentally validated. They concluded that densely-packed pin fins are more adequate for high Reynolds number flows while sparse pin fins are more suited to low Reynolds number flows. Prasher et al. [14] performed an extensive experimental study with a silicon-based, staggered, micro pin fin array under water flow. The micro pin fins tested were both circular and square shaped. The pin fin diameters ranged from $55 \mu \mathrm{m}$ to $153 \mu \mathrm{m}$, and the height-to-diameter ratios varied from 1.3 to 2.5 . The results were compared in terms of a thermal performance parameter that represents heat transfer per unit pumping power. Wang et al. [15] fabricated short copper micro pin fins on a copper plate using an electroplating technique. Heat transfer experiments were conducted with these micro pin fin coupons in a rectangular channel with different pin fin heights, diameters, spacing, and shapes. The optimized design achieved 78.3\% improvement in heat transfer with a pressure drop increase of 7.8\%. Galvis et al. [16] attempted to numerically predict the thermal and hydraulic performance of micro heat exchanger that consists of narrow planar channel with parallel flat plates and small cylindrical pin fins under air flow. The pin fin array was staggered with diameters of $0.5,5.1$, and $8.5 \mathrm{~mm}$. The diameter to height ratio was 1.0. The investigated Reynolds numbers were between 4,000 and 50,000. The 
result indicated that the pin fin arrays with the diameter of $0.5 \mathrm{~mm}$ can improve thermal performance by a factor of 4 compared to that of smooth channel counterpart. Tullius et al. [17] performed a modeling based optimization study of micro fins in a minichannel considering different parameters such as fin geometry, fin to channel height ratio, fin width and spacing, and fin material. The channel flow was laminar air flow. Their results showed that increasing fin height and decreasing fin width and spacing increased the Nusselt number but led the significant pressure drop. The elliptic and circular fin shapes minimized the pressure drop with considerably enhanced heat transfer performance. Adewumi et al. [18] performed a numerical study to optimized a micro channel heat sink with micro pin fin arrays. The micro pin fins considered here have the heights between 30 and $160 \mu \mathrm{m}$, and the diameters between 40 and $60 \mu \mathrm{m}$. They first optimized the plain surface micro channel and then introduced the micro pin fins in the channel for further optimizations. Their results were expressed in terms of the Bejan number and showed that the minimum channel peak temperature decreased as the Bejan number increased. Wang et al. [19] experimentally and numerically investigated the thermal and hydraulic characteristics of heat sinks with micro-ribs. Their micro-ribs have rectangular, triangular, and semicircular cross-sectional shapes. The rib height, width, and spacing are 100, 200, and $800 \mu \mathrm{m}$, respectively. These micro-ribs were fabricated on the wall of micro channels by a MEMS process. The study showed that the micro-rib is an effective way to enhance heat transfer performance of the micro channels but only suitable for the operating condition of Reynolds numbers less than 600. Wan and Joshi [20] focused on square shaped micro pin fins and conducted a parametric study considering diameter, height, spacing, and Reynolds number. The paper compared its hydraulic and thermal performance to those of circular micro pin fins in terms of friction factor and Colburn $\mathrm{J}$ factor. The results showed that the circular micro pin fins 
has better thermal performance with the same pumping power. Yeom et al. [21] demonstrated cooling performance of micro pin fin surfaces in a narrow channel coupled with an in-channel agitation plate oscillating at a high frequency. Two different geometries of staggered micro pin fin arrays were fabricated having area increases of $38 \%$ and 104\%. For low Reynolds number laminar flows, the micro pin fin surfaces showed similar thermal performance to that of a plain surface. Once the flow rate increased and Reynolds numbers reached turbulent-like levels, the micro pin fin surfaces provided maximum heat transfer augmentation of $73 \%$ over the plain surface. The more densely the pin fins are packed, the smaller the heat transfer enhancement, since they tend to have more bypass over the bank of micro pin fins due to the high flow resistance through the pin fin structures. This observation matches well with previous studies done by Moores and Joshi [10] and Peles et al. [13]. The micro pin fin surfaces coupled with an oscillating agitator plate enhanced thermal performance values more than $220 \%$, compared to non-agitated plain surface values. Yeom et al. [22] performed system-level heat transfer experiments with a multi-channel, fan-assisted heat sink equipped with micro pin fin surfaces and with in-channel agitator blades translating in an oscillating manner. The translational oscillation of the blade structure was realized using a piezoelectric actuator [23]. The micro pin fins were in a staggered array having height, diameter, and pitch of $250 \mu \mathrm{m}, 500 \mu \mathrm{m}$, and 1500 $\mu \mathrm{m}$ in a channel $52 \mathrm{~mm}$ long, $4.3 \mathrm{~mm}$ high, and $20 \mathrm{~mm}$ wide. The active heat sink system reduced the thermal resistance by $45 \%$, compared to that with a plain surface without agitation. The study also showed that utilizing the micro pin fin surfaces and agitators is a more efficient way of obtaining better cooling performance than just increasing the flow rate by boosting suction power. The major take-away from the literature reviewed so far is that micro pin fins with a staggered array provides better heat transfer performance than with an in-lined array of 
micro pin fins. Another is that the area increase due to an increased number of micro pin fins is not always a positive factor for enhancing cooling performance as it is also associated with increased flow resistance and bypass of air over the bank of micro pin fins.

In this study, we focus on thermal and frictional characteristics of micro pin fin arrays in a long and narrow rectangular channel that simulates a channel of fan-assisted, computer-cooling heat sink. Generally, a heat sink possesses a large number of channels and the through-flow is generated by an external blower or suction fan. It is apparent that numerous micro pin fins positioned on the surfaces of the heat sink would increase heat transfer area dramatically and could readily enhance cooling capability. Totally, eleven different configurations of staggered micro pin finned channels were fabricated by electroplating copper onto a thin copper substrate. Heat transfer and pressure drop characteristics of such micro pin fin arrays in an air-flow channel are documented. These data and the conclusions based upon them provide further insight toward improved design of enhanced heat transfer mini-channels for such applications as electronics cooling.

\section{Experimental apparatus}

\subsection{Heat transfer experimental set up}

An overall schematic of the heat transfer experiment is shown in Figure 1. The test section is a narrow rectangular channel with a micro pin-fin coupon housed in the middle of the channel. An air flow, created by an external pump, enters from the left side of the channel. The test section was designed to simulate a portion of the heat sink channel. The pressure drop through the test section of the channel is measured with a U-shape micro-manometer filled with dyed water. More explanations on pressure drop measurement will be presented in the following sections. A volumetric flow rate meter and a valve are positioned between the test section and 
the pump. All thermocouples and heaters in the experimental facility are connected to data acquisition equipment. A detailed illustration of the test section is featured in Figure 2. A long, rectangular copper block is utilized to create a heat flow path from a heater to the convectivelycooled surface. A cartridge heater is inserted at the end of the copper block providing heat input to the system. The other end of the copper block is a thin copper plate wall of the channel with micro pin fins.

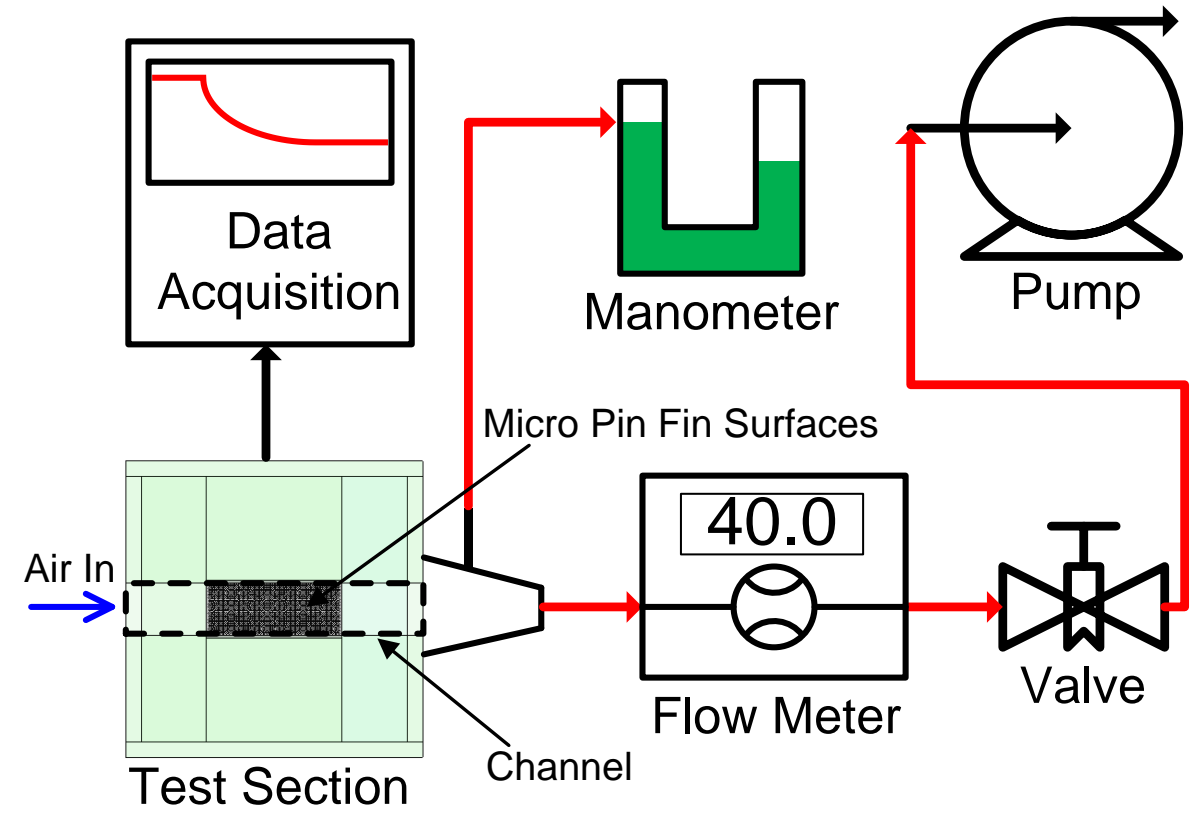

Fig. 1 The diagrams of heat transfer experiment facility 


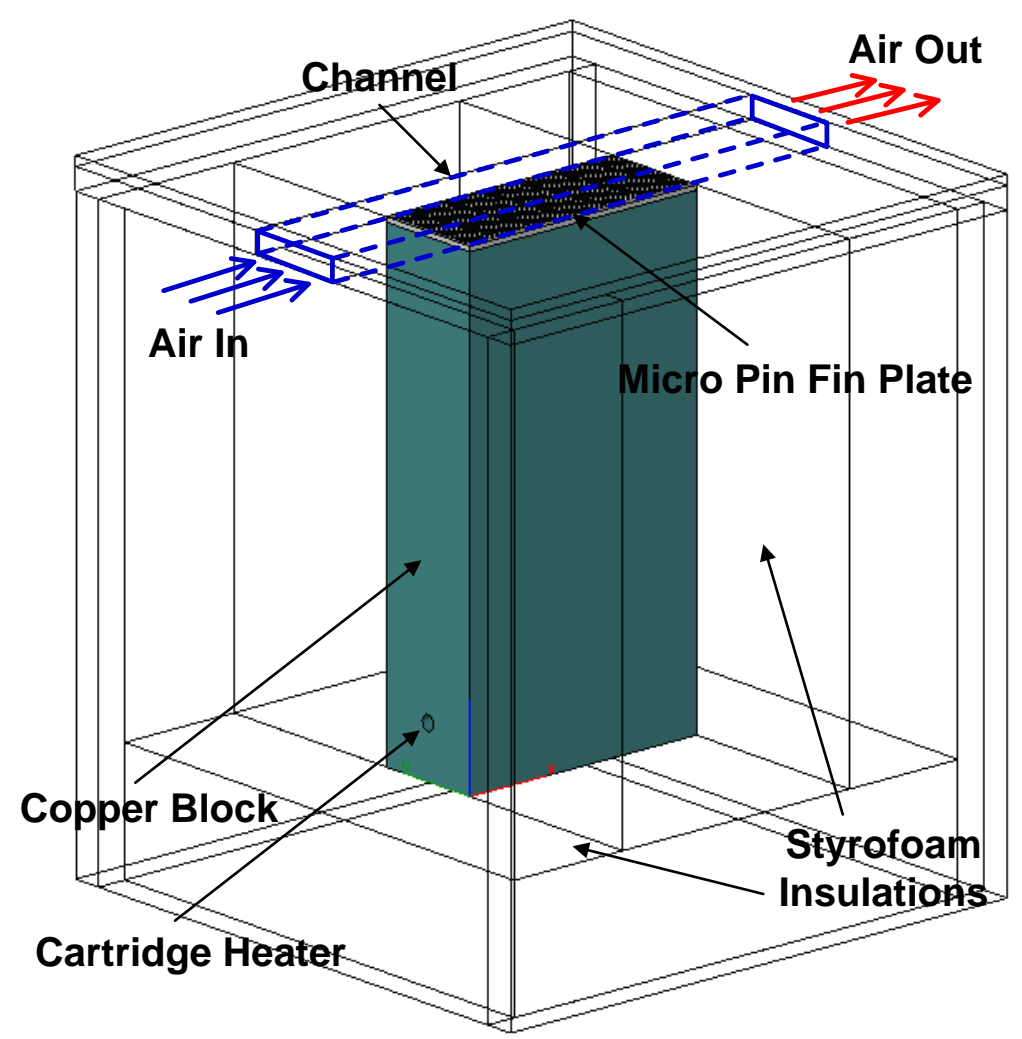

Fig. 2 Test section of the heat transfer experiment

The assembly is made so that it is possible to easily replace the thin micro pin-fin plates with other configurations for continued experiments. The channel is created using the micro pin-fin surface and transparent plastic plates for the other three surfaces. The channel has adiabatic extensions upstream and downstream of the test section to give fully developed flow in the channel upstream of the micro pin-fin surface. The unheated channel surfaces and the heater block are enclosed by thick Styrofoam insulation to eliminate heat loss. Temperatures are measured $1.0 \mathrm{~mm}$ below the contact surface between the micro pin-fin plate and the copper block, as shown in Figure 3. From these temperature measurements, surface temperatures of the micro pin-fin surface are found by extrapolation and heat flux is computed. These are taken as the base temperatures of the micro pin-fins plate. Two thermocouples measure flow inlet temperature and one thermocouple measures flow outlet temperature. Figures 3(a) and (b) show the side and front 
views of the channel, respectively. The micro pin-fin plate is attached to the copper block using a thermal paste to minimize thermal contact resistance at the joint. The heated length $(\mathrm{L})$, channel width (W), and channel height (Y) are $52 \mathrm{~mm}, 20 \mathrm{~mm}$, and $4.3 \mathrm{~mm}$, respectively. Figures 3(c) and (d) show the configuration of micro pin fins. The plate has a base thickness of $1.0 \mathrm{~mm}$. Eleven micro pin fin plates were fabricated and tested. All the micro pin fin arrays are of a staggered configuration since thermal performance of the staggered array was shown in the literature to be superior to in-lined arrays, as discussed previously. The quantities ' $H$ ', ' $D$ ' and ' $S$ ' are pin fin height, diameter, and pitch (in both horizontal and vertical directions), respectively. The dimensions of the micro pin fin arrays are listed in Table 1, as well as their porosity and the values of heat transfer area increase they offer.

Table 1. Dimensions of micro pin fins

\begin{tabular}{ccccccc}
\hline Micro Pin Fin & $\begin{array}{c}\mathbf{H} \\
(\boldsymbol{\mu} \mathbf{m})\end{array}$ & $\begin{array}{c}\mathbf{D} \\
(\boldsymbol{\mu} \mathbf{m})\end{array}$ & $\begin{array}{c}\mathbf{S} \\
(\boldsymbol{\mu} \mathbf{m})\end{array}$ & $\mathbf{S} / \mathbf{D}$ & $\begin{array}{c}\text { Porosity } \\
(\boldsymbol{\%})\end{array}$ & $\begin{array}{c}\text { Area Increase } \\
(\boldsymbol{\%})\end{array}$ \\
\hline H150D75 & 150 & 75 & 450 & 6 & 4.2 & 29.7 \\
H150D150 & 150 & 150 & 450 & 3 & 16.8 & 63.3 \\
H150D200 & 150 & 200 & 600 & 3 & 16.8 & 46.5 \\
H250D250 & 250 & 250 & 750 & 3 & 16.8 & 63.3 \\
H250D400 & 250 & 400 & 1200 & 3 & 16.8 & 38.1 \\
H350D350 & 350 & 350 & 1050 & 3 & 16.8 & 63.3 \\
H350D450 & 350 & 450 & 1350 & 3 & 16.8 & 48.4 \\
H400D250 & 400 & 250 & 750 & 3 & 16.8 & 103.6 \\
H400D400 & 400 & 400 & 1200 & 3 & 16.8 & 63.3 \\
H400D600 & 400 & 600 & 1800 & 3 & 16.8 & 40.9 \\
H400D700 & 400 & 700 & 2100 & 3 & 16.8 & 34.5 \\
\hline
\end{tabular}

One basic unit of the pin fin array used for computing porosity contains one fin in the center and four quarter-fins at each corner of a square area with an edge length of ' $S$,' as shown in Figure $3(d)$. 
(a) Side View of Channel

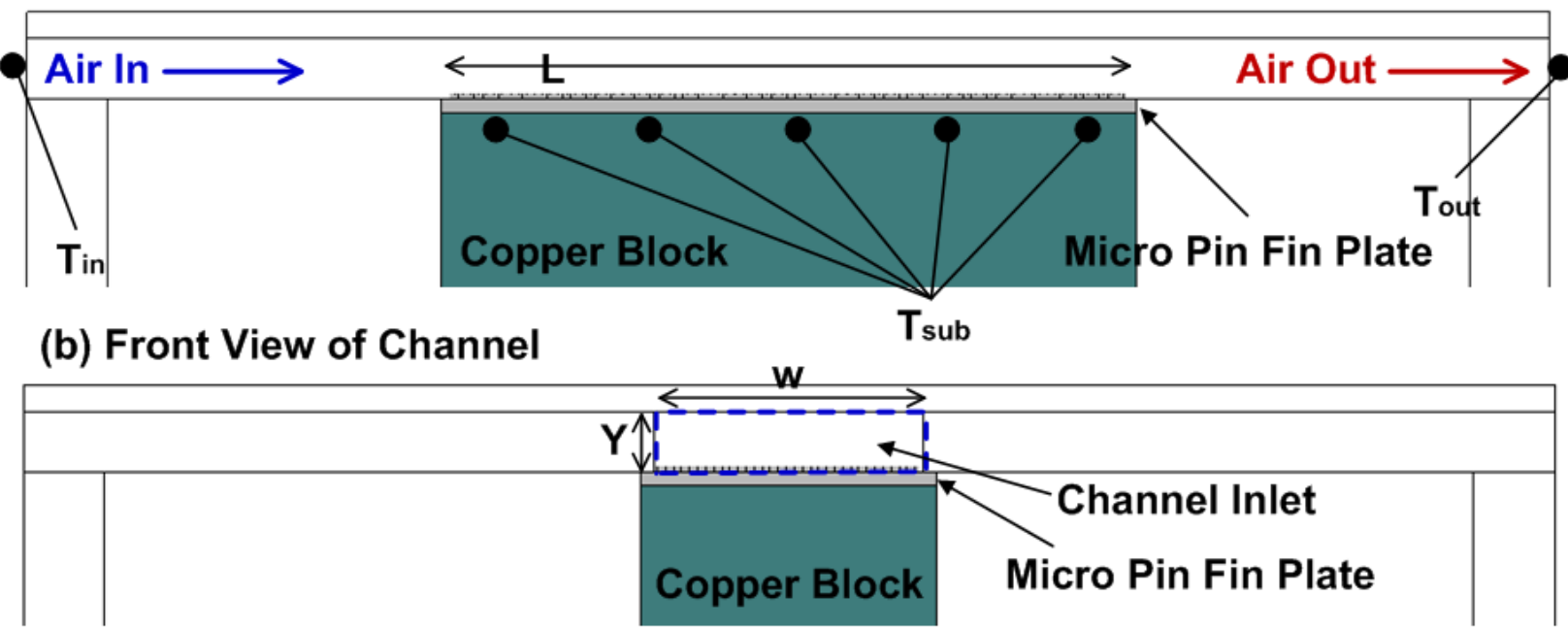

(c) Micro Pin Fin Plate

(d) Micro Pin Fin Configuration
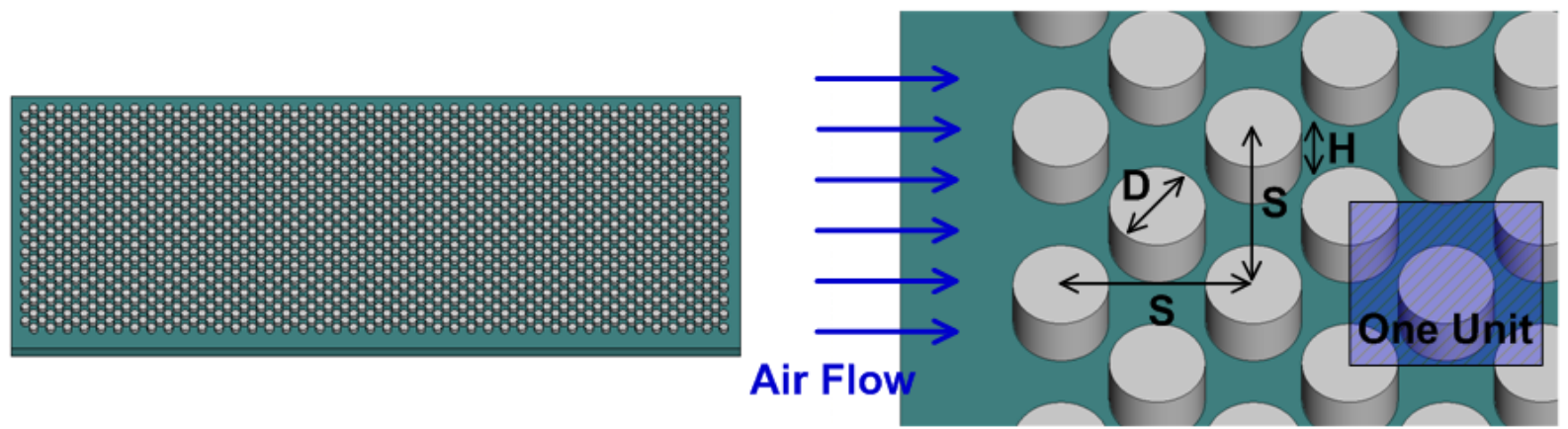

Fig. 3 Configurations of the channel and micro pin fins

Herein, porosity $(\xi)$ is defined as a ratio of pin fin occupied area to base area:

$$
\xi=N_{m p} \pi(D / 2)^{2} / A_{b a s e}
$$

where, $N_{m p}$ and $A_{\text {base }}$ are the number of pin fins and the base area of the micro pin-fin plate, respectively. The number of pin fins on the plate is calculated as:

$$
N_{m p}=2\left(A_{b a s e} / S^{2}\right)
$$

Eleven micro pin fin arrays are classified with different pin fin heights of $150 \mu \mathrm{m}, 250 \mu \mathrm{m}, 350$ $\mu \mathrm{m}$ and $400 \mu \mathrm{m}$. Each group has several pin fin diameters, as listed in Table 1. All of the cases have the same $S / D$ ratio of 3 except for case H150D75, which has an $S / D$ ratio of 6 . The area increase over an un-finned surface is computed as:

$$
\text { Area increase }(\%)=\left(N_{m p} \pi D H / A_{\text {base }}\right) \times 100
$$


Among the eleven samples, case H400D250 has the largest area increase of $103.6 \%$ and case H150D75 has the smallest area increase of $29.7 \%$.

\subsection{Fabrication of micro pin fin structures}

Photolithographic techniques are suitable for high-aspect-ratio microstructures and highvolume batch production since they are faster than Electrical Discharge Machining (EDM), casting, extrusion, sintering and other machining techniques. Recently, fabricating pin fin structures onto silicon substrates was attempted by the Deep Reactive Ion Etching (DRIE) process or by the nickel plating LIGA processes $[24,25]$. In the present work, copper micro pin fins are fabricated on a copper substrate, capitalizing on copper's high thermal conductivity and low cost. The LIGA approach was used. The fabrication process is shown in Figure 4. First, the copper substrate is cut as $102 \mathrm{~mm}$ (4-inch) silicon wafers to make the fabrication process easier. Next, the substrate is cleaned using acetone, methanol, isopropyl alcohol, potassium hydroxide ( $2 \%$ weight ratio) and sulfuric acid (10\% weight ratio). As the next step, a protective layer of $\mathrm{Ti}$ is deposited on the copper wafer after wafer cleaning (Figure 4(a)). A KMPR photoresist (MicroChem corp.) mold is next developed on the copper substrate, as shown in Figure 4(b). The Ti metal layer is then etched with diluted hydrofluoric acid (Figure 4(c)). Micro pin fins are then electroplated in a copper plating bath. Finally, the KMPR photoresist is removed and the copper micro pin fin array is obtained, as shown in Figure 4(d). An SEM (Scanning Electron Microscope) image of the fabricated micro pin fin array is shown in Figure 4(f). 


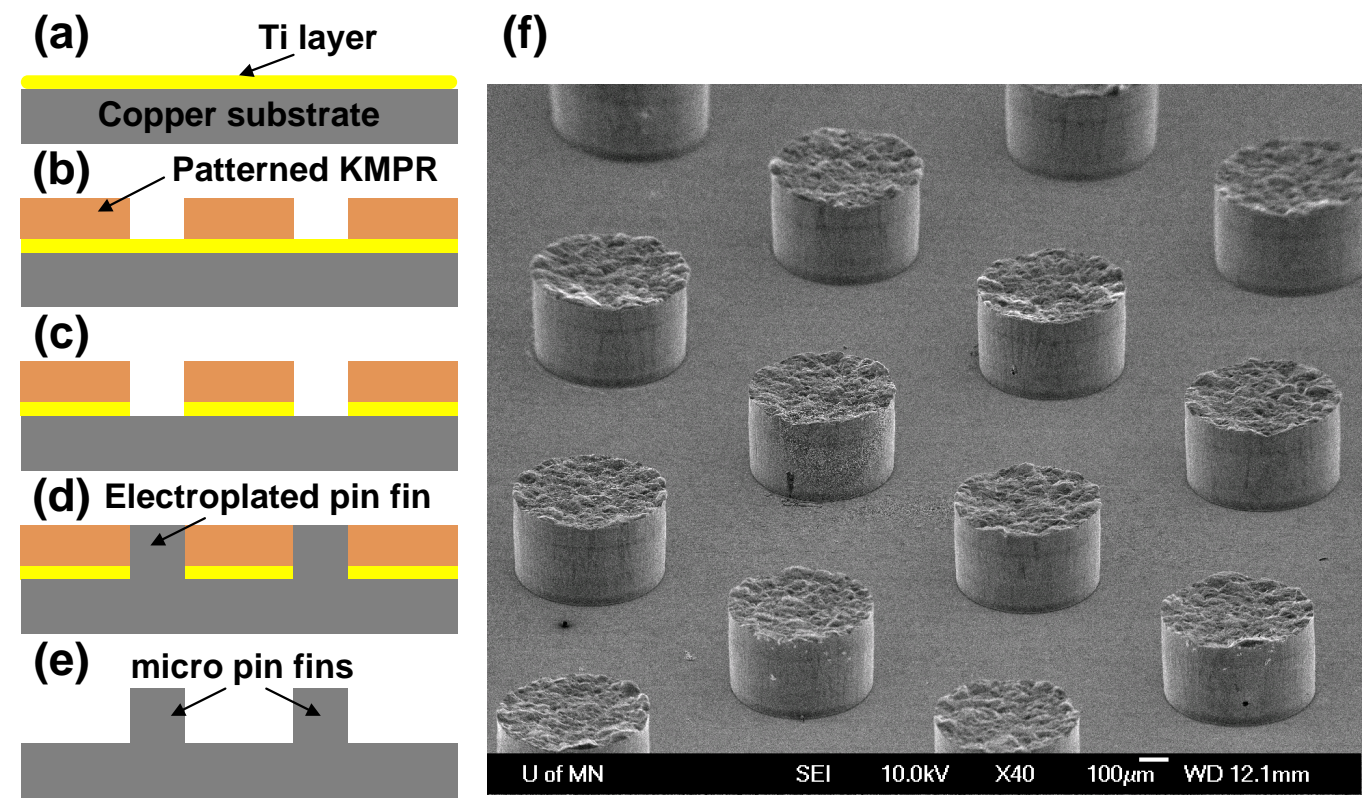

Fig. 4 Fabrication process of the copper micro pin fin plate, (a) Ti metal layer deposition, (b) KMPR photoresist mold development, (c) Ti layer etching, (d) Copper pin fin electroplating, (e) KMPR photoresist removal, (f) SEM image of micro pin fin array

\section{Data reduction and uncertainty analysis}

Heat transfer experiments are performed with the micro pin fin plates and corresponding heat transfer coefficients and Nusselt numbers are presented to investigate the thermal performance of the micro pin-fin structures. Heat transfer coefficients $(h)$ are computed with the Log Mean Temperature Difference (LMTD) method as:

$$
h=q / A \cdot \Delta T_{L M T D}
$$

where $q, A$, and $\Delta T_{L M T D}$ represent heat transfer from the cartridge heater, the convection surface area, and the log mean temperature difference, respectively. The log mean temperature difference is:

$$
\Delta T_{L M T D}=\left(\Delta T_{2}-\Delta T_{1}\right) / \ln \left(\Delta T_{2} / \Delta T_{1}\right)
$$

The temperature differences between flow bulk mean temperature and surface temperature at the inlet and outlet are expressed as below: 


$$
\Delta T_{1}=T_{\text {sur }}-T_{\text {in }}, \Delta T_{2}=T_{\text {sur }}-T_{\text {out }}
$$

As noted previously, the surface temperatures $\left(T_{s u r, i}\right)$ are extrapolated from the temperatures $\left(T_{s u b, i}\right)$ measured in the copper block under the micro pin fin plate. The temperature drop at the interface between the copper block and the micro pin-fin plate due to the thermal contact resistance is computed and included in the data reduction. Therefore, the extrapolated surface temperatures of the micro pin fin base are:

$$
T_{s u r, i}=T_{s u b, i}-\frac{q}{A_{c}}\left(\frac{l_{s u b}}{k}+\frac{x}{k_{p}}\right)
$$

where $l_{s u b}, x, k, k_{p}$, and $A_{c}$ are the distance between the micro pin-fin plate and temperature measuring position, the gap distance at the interface, copper thermal conductivity, thermal paste conductivity, and the cross sectional area of the copper block, respectively. The extrapolated surface temperatures are averaged as:

$$
T_{\text {sur }}=\frac{\sum_{i=1}^{N} T_{\text {sur }, i}}{N}, N=10
$$

Accordingly, Nusselt number is calculated as:

$$
N u=h d / k_{f}
$$

where $d$ and $k_{f}$ are the hydraulic diameter in the test section and thermal conductivity of air. A flow resistance study over the plain and micro pin fin surfaces is performed by measuring the static pressure difference across the test section. For clarification, the test section refers to the heated section of the channel marked as L in Figure 3(a). The study can be done by either directly measuring the pressure drop across the test section or subtracting all other pressure losses of the channel except for the test section loss from the entire channel static pressure drop. Herein, we use the latter for improved testing efficiency and accuracy since embedding pressure 
taps close to the test section in the channel makes the replacement of micro pin-fin coupons cumbersome with this test facility. However, the direct pressure drop measurement was made only for the plain surface case, and this was used to evaluate the other pressure losses of the channel. First, a pressure tap was embedded in the flow passage at the outlet of the channel to measure the entire static pressure drop across the channel for the plain surface case. Next, the pressure drop was measured across only the test section for the same plain surface by locating two pressure taps immediately before and after this area. The sum of all the pressure losses in the channel other than the test section pressure drop can be computed by subtracting the test section pressure drop from the entire static pressure drop across the channel measured for the plain surface. The measured static pressure at the channel outlet relative to the inlet pressure, the ambient pressure, is calculated as:

$$
P_{\text {static }}=2 z g \cdot\left(\rho_{\text {water }}-\rho_{\text {air }}\right)
$$

where $z, g, \rho_{\text {water }}$, and $\rho_{\text {air }}$ are the water elevation reading from the manometer, the standard gravitational acceleration, the water density and the air density, respectively. The pressure drop over the test section can be computed similarly as:

$$
\Delta P_{\text {test }}=2 z_{\text {test }} g \cdot\left(\rho_{\text {water }}-\rho_{\text {air }}\right)
$$

where $z_{\text {test }}$ is the manometer reading based upon pressure difference from the end of the test section relative to the starting point. The pressure losses of the channel excluding the test section loss can be calculated by subtracting Equation (11) from Equation (10) as:

$$
\Delta P_{\text {loss }}=P_{\text {static }}-\Delta P_{\text {test }}
$$

This loss term includes upstream/ downstream frictional losses and entrance loss as well as any other possible additional losses existing in the channel due to non-continuous walls. For all other micro pin fin surfaces, the static pressure was measured at the end of the channel using Equation 
(10) and the pressure loss calculated by Equation (12) was subtracted to obtain the pressure drop of the test section with the micro pin fin surfaces. The friction factor of the test section channel was calculated by:

$$
f=2 d \Delta P_{\text {test }} / \rho_{\text {air }} L V_{\text {test }}^{2}
$$

where $L$ and $V_{\text {test }}$ are the test section length and flow velocity in the test section.

An uncertainty analysis is done on the heat transfer coefficients and pressure drop calculations based on the standard practice of propagation of uncertainty. The cartridge heater utilizes alternating current (AC) and time-varying voltage and current are measured with an oscilloscope. The resistance of $0.2 \Omega$ with $0.1 \%$ of error was set to measure the current through the heater. The oscilloscope has a measurement accuracy of $3 \%+1 \mathrm{mV}$. The corresponding uncertainty in power input is calculated as $4.4 \%$. The convection surface area has $4 \%$ uncertainty and the uncertainty of temperature measurements is conservatively set to $0.5^{\circ} \mathrm{C}$. As a result, the total uncertainty in heat transfer coefficient is computed to be $6.1 \%$ and the pressure drop uncertainty is $6.2 \%$.

\section{Experimental results}

\subsection{Heat transfer coefficients}

Heat transfer coefficients for the micro pin fin arrays taken under four different throughflow rates at 10 LPM, 20 LPM, 40 LPM, and 60 LPM are compared for four groups of surfaces as classified according to pin fin height. The flow rates and their corresponding inlet average velocities and Reynolds numbers are summarized in Table 2. Two different types of heat transfer coefficients are calculated, one using the base area $\left(\mathrm{A}_{\text {base }}\right)$ of the micro pin finned plates and another using the actual heat transfer area $\left(\mathrm{A}_{\text {actual }}\right)$ of the micro pin fins plus the exposed base area. The heat transfer coefficients calculated using the base area account for heat transfer 
enhancement due to both area increase and fluid dynamic effects, while the heat transfer coefficients based on the actual heat transfer area account only for the fluid dynamics effects. Figure 5 shows the heat transfer coefficients of the group with a height of $150 \mu \mathrm{m}$.

Table 2. Channel Through-Flow Conditions for Heat Transfer Experiments

\begin{tabular}{ccccc}
\hline Flow Rate (LPM) & $\mathbf{1 0}$ & $\mathbf{2 0}$ & $\mathbf{3 0}$ & $\mathbf{4 0}$ \\
\hline Inlet Flow Velocity $(\mathbf{m} / \mathbf{s})$ & 1.9 & 3.9 & 7.8 & 11.6 \\
Reynolds Number & 823 & 1646 & 3293 & 4938 \\
\hline
\end{tabular}

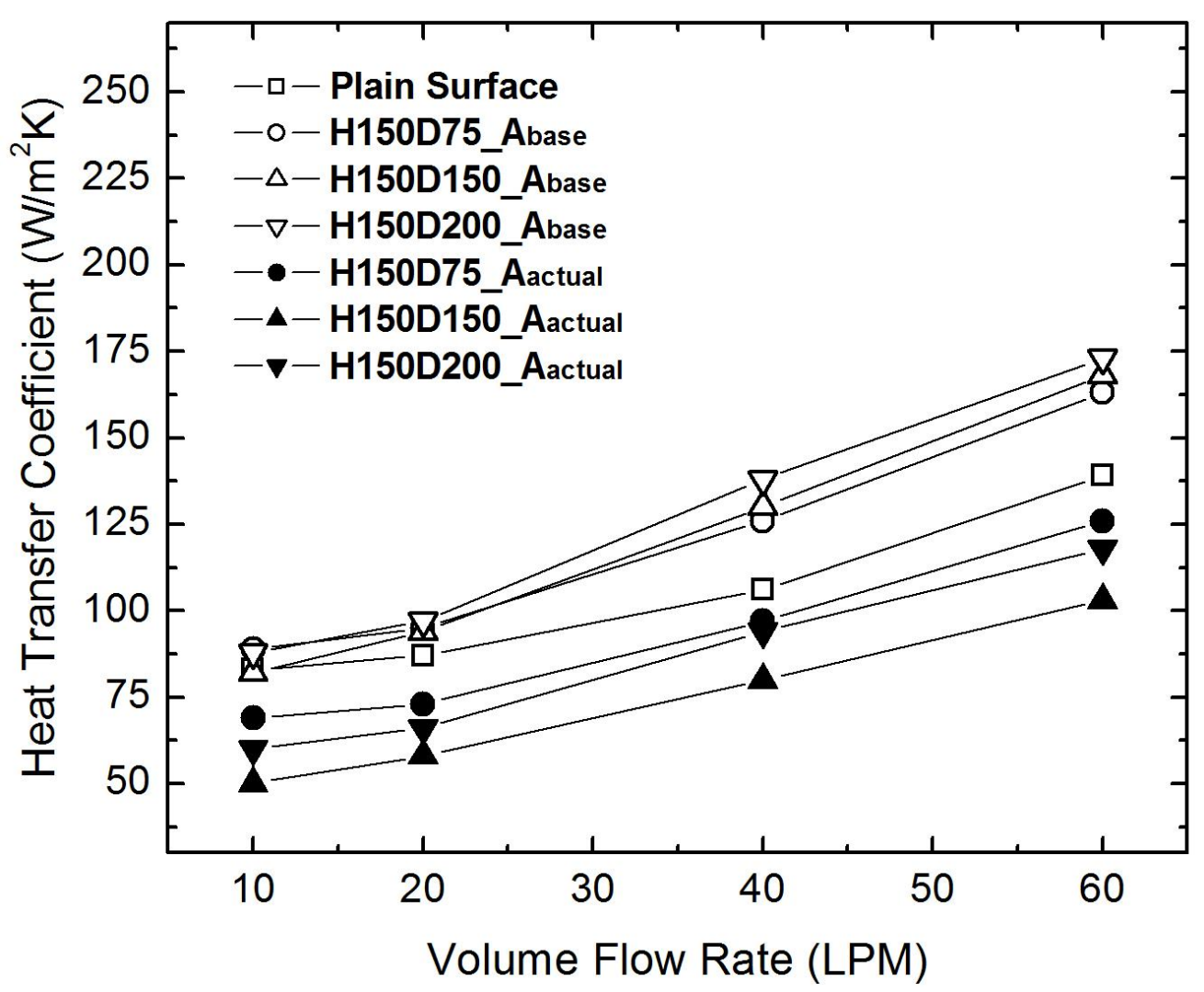

Fig. 5 Heat transfer coefficient comparisons of micro pin fin arrays with the height of $150 \mu \mathrm{m}$ and different fin diameters

It is confirmed that micro pin fins with a larger diameter provide larger heat transfer rate at a fixed height when the coefficients are calculated based on the base area. Case H150D200, which has the largest heat transfer coefficient among the three values based on the base area, has the 
smallest heat transfer coefficient when the calculation is based on the total heat transfer area. On the other hand, case H150D75, which has the smallest heat transfer coefficient based on the base area, has the largest heat transfer coefficient based on the total heat transfer area. Thus, case H150D75 generates the strongest fluid dynamics effects, such as flow mixing and wall turbulence, but has the smallest area increase (only about 30\%), resulting in the lowest heat transfer coefficients in this group. The large heat transfer rate of H150D200 is mainly due to the area increase of about $63 \%$. Overall, the group with a height of $150 \mu \mathrm{m}$ shows a $20 \%$ heat transfer enhancement at higher through-flow rates of 40 and 60 LPM. Figure 6 presents the results of the groups with a height of $250 \mu \mathrm{m}$.

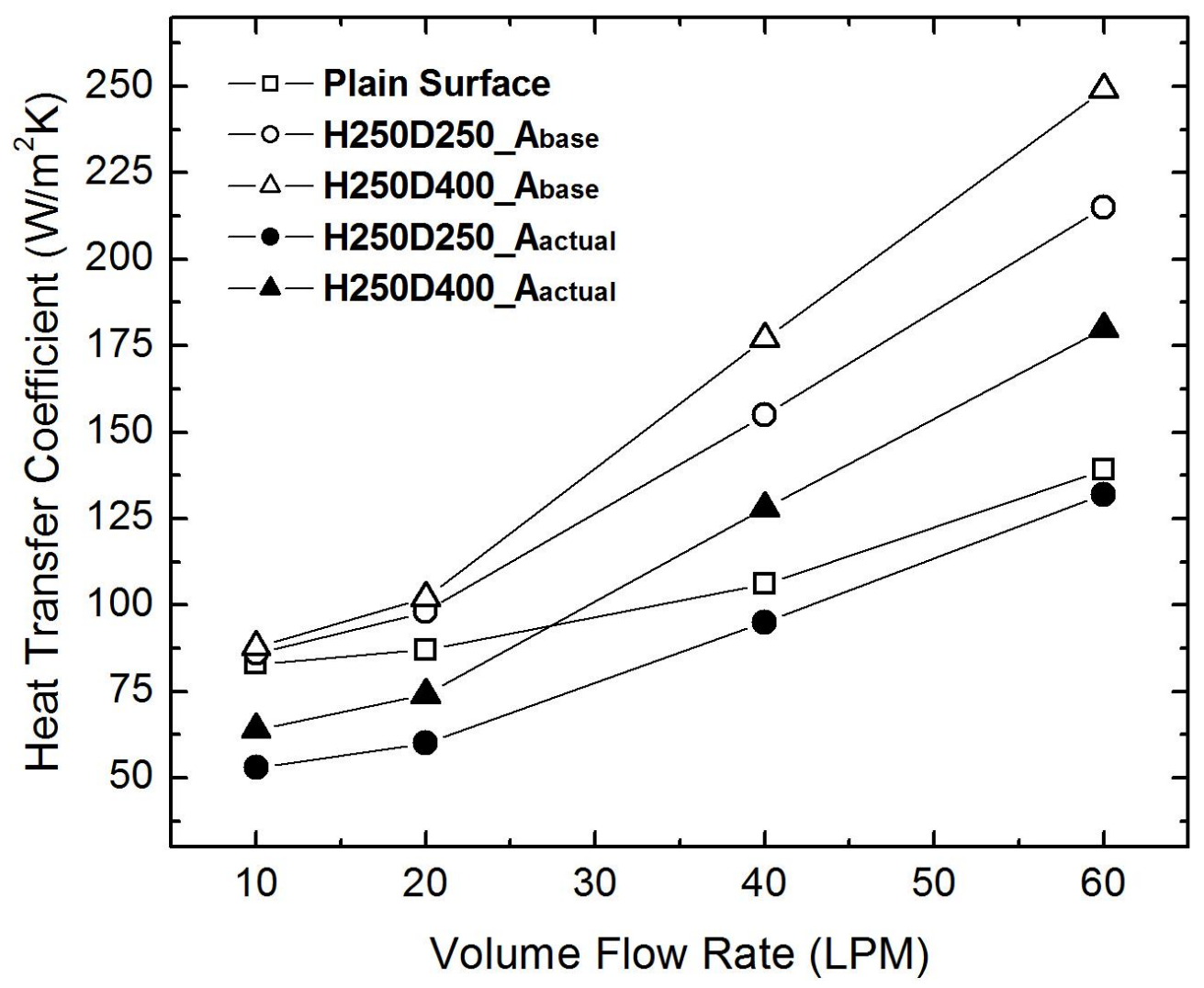

Fig. 6 Heat transfer coefficient comparisons of micro pin fin arrays with the height of $250 \mu \mathrm{m}$ and different fin diameters 
In terms of the heat transfer coefficient based on the base area, a larger diameter gives larger heat transfer rates for all the through-flow rates, even though the area increase of the H250D400 case is much smaller than that of the H250D250 case. This implies that fluid dynamics effects generated from the H250D400 surface overwhelm the area increase of the H250D250 case. This could be confirmed again from the heat transfer coefficients based on the increased area. The H250D400 case showed much larger heat transfer coefficients than those of the H250D250 case. From the results, it is also notable that fluid dynamics effects for enhancing heat transfer performance become more dominant at higher through-flow rates. The case of H250D400 provides the highest heat transfer performance among all the eleven micro pin fin arrays when calculated based on the base area, in spite of its small area increase of only $38 \%$ over the base area. With a through-flow rate of 60 LPM, the H250D400 case enhances heat transfer coefficients by $79 \%$ over those of the plain surface. The heat transfer test results of the groups with pin fin heights of $350 \mu \mathrm{m}$ and $400 \mu \mathrm{m}$ are shown in Figures 7 and 8 . 


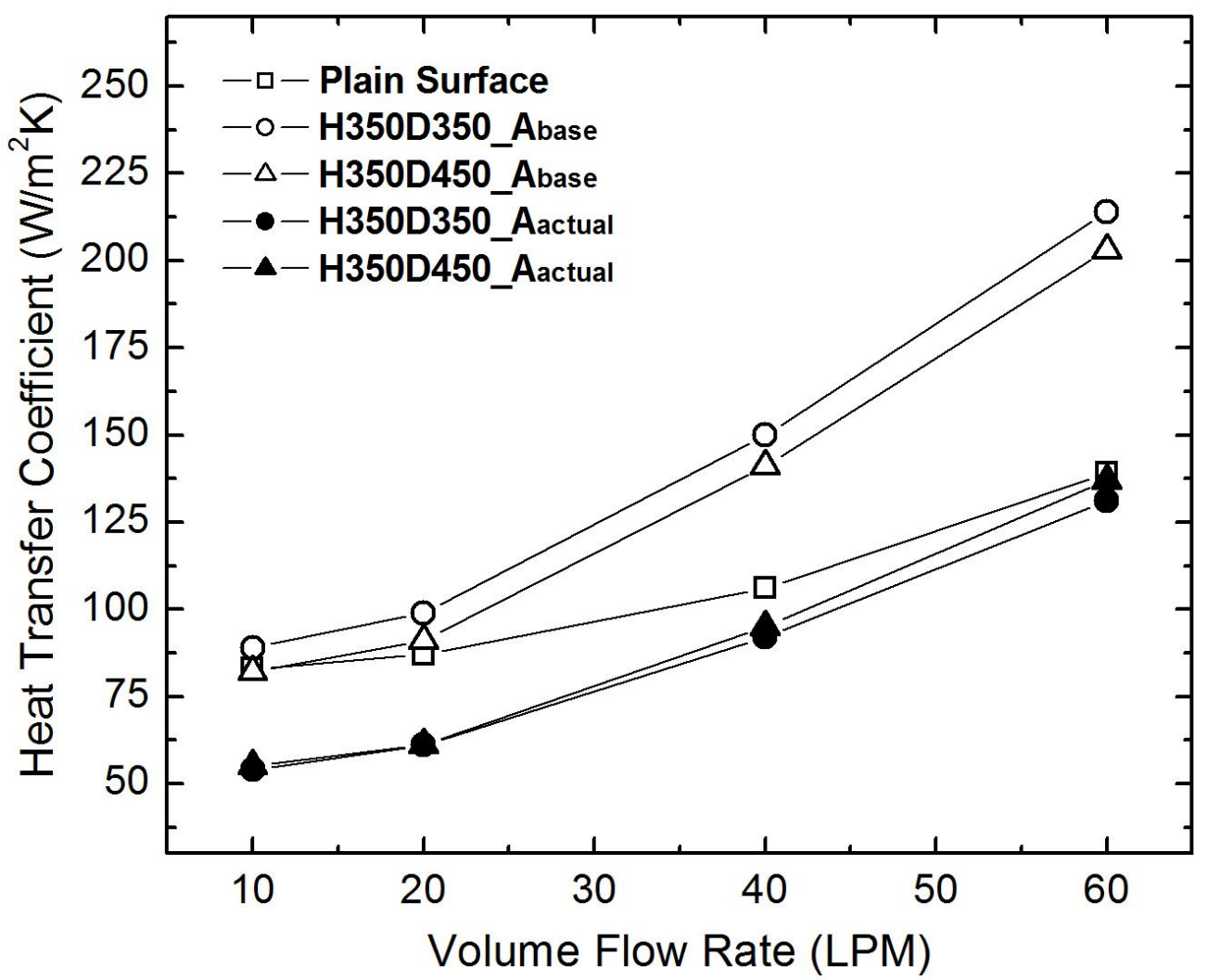

Fig. 7 Heat transfer coefficient comparisons of micro pin fin arrays with the height of $350 \mu \mathrm{m}$ and different fin diameters 


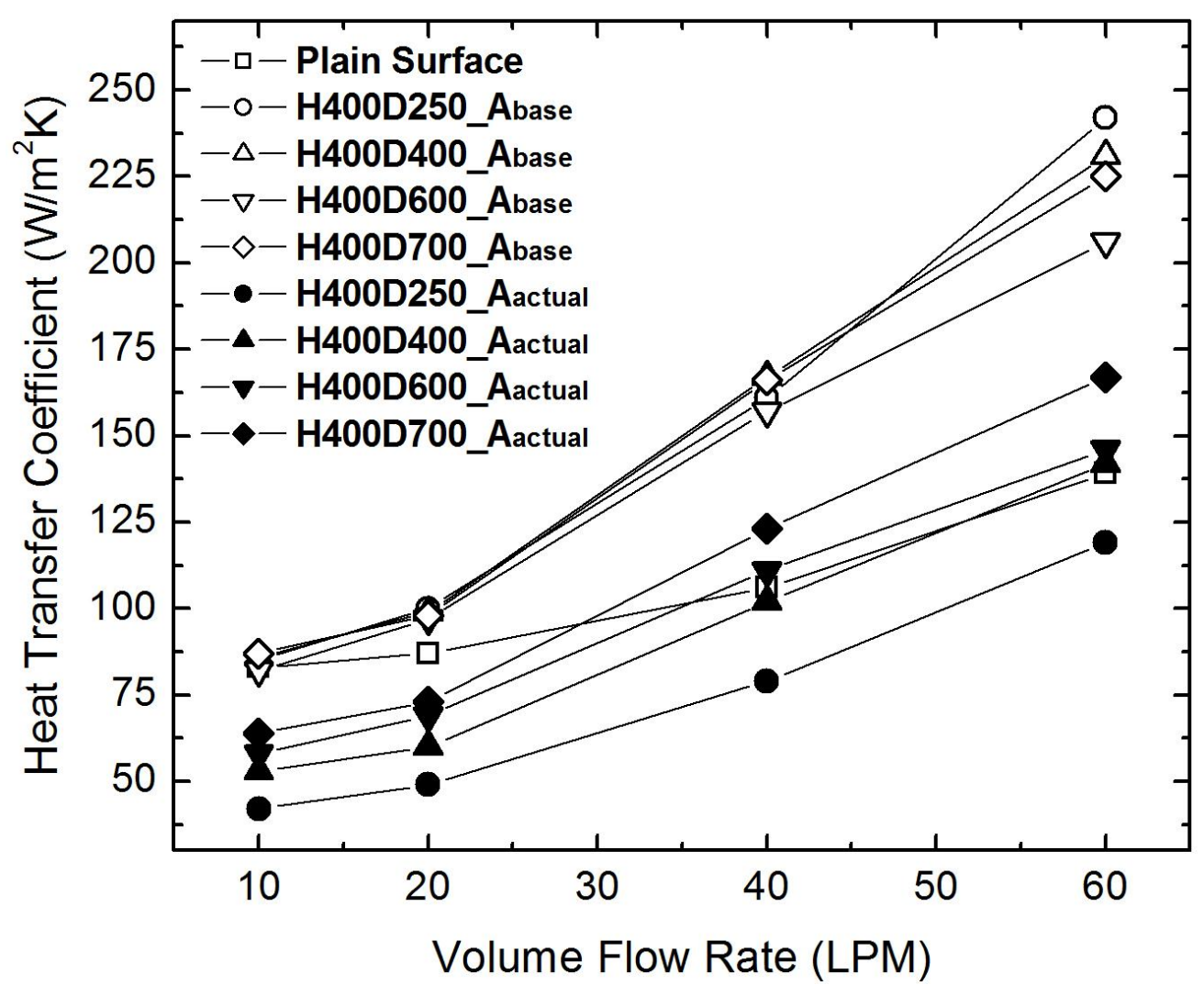

Fig. 8 Heat transfer coefficient comparisons of micro pin fin arrays with the height of $400 \mu \mathrm{m}$ and different fin diameters

The two cases in the group of $350 \mu \mathrm{m}$ height provide similar thermal performance as their diameter change is small compared to the pin fin height. The last group, with a pin fin height of $400 \mu \mathrm{m}$, has the widest range of diameter, from $250 \mu \mathrm{m}$ to $700 \mu \mathrm{m}$. Overall heat transfer performance computed based on the base area suggests that all four cases show comparable performance for all through-flow rates, except for the 60 LPM case, where the case with a diameter of $250 \mu \mathrm{m}$ shows the largest improvement of $74 \%$. This is a slightly lower improvement than that of the H250D400 case. Unlike the similar overall heat transfer performance values that were based on the base area, strong variations among the cases could be found when the heat transfer coefficients are based on the actual heat transfer area. The H400D250 case, which shows the greatest enhancement overall, has a smallest heat transfer 
coefficient based on the total heat transfer area, indicating that the major heat transfer enhancement of this case is the area increase (103\%) rather than increases due to fluid dynamics effects. From the given heat transfer coefficient results, it is not easy to sort out a dependence of the overall heat transfer on pin fin height or pin fin diameter. However, one apparent pattern could be found from the heat transfer coefficients based on the actual heat transfer area (Figures 5, 6, 7, and 8), that fluid dynamics effects for enhancing heat transfer performance increase with increasing pin fin diameter at a fixed height. One exception is found from the group with a height of $150 \mu \mathrm{m}$ (Figure 5). The surface of the H150D75 case shows the largest heat transfer coefficient based on actual heat transfer area, in spite of its smallest diameter among the group. However, this exception is acceptable as this case possesses an $S / D$ ratio of 6 , while all the other cases have an $S / D$ ratio of 3 . It is interesting to see that a larger $S / D$ ratio and smaller porosity generate a stronger fluid dynamics effect for enhancing heat transfer performance. It is presumed that this is due to a deeper penetration and reduced bypassing of the flow for the S/D = 6 case.

\subsection{Pressure drop and friction factor}

Measured pressure drops over the micro pin fin arrays are shown in Figure 9 for different flow Reynolds numbers. Pressure drop differences between the micro pin fin arrays are small and even negligible in the lower Reynolds number ranges, below 2000, which are in the laminar flow regime. On the other hand, differences in pressure drop between the micro pin fin arrays become more obvious in the turbulent flow regime. Overall, it is not difficult to find that the H400D250 case, showing the largest heat transfer enhancement, generates the largest pressure drop among the eleven cases. More detailed comparisons of pressure drop at the higher Reynolds numbers, above 4000, are shown in Fig. 10. The results are classified into four different groups based on a pin fin height. 


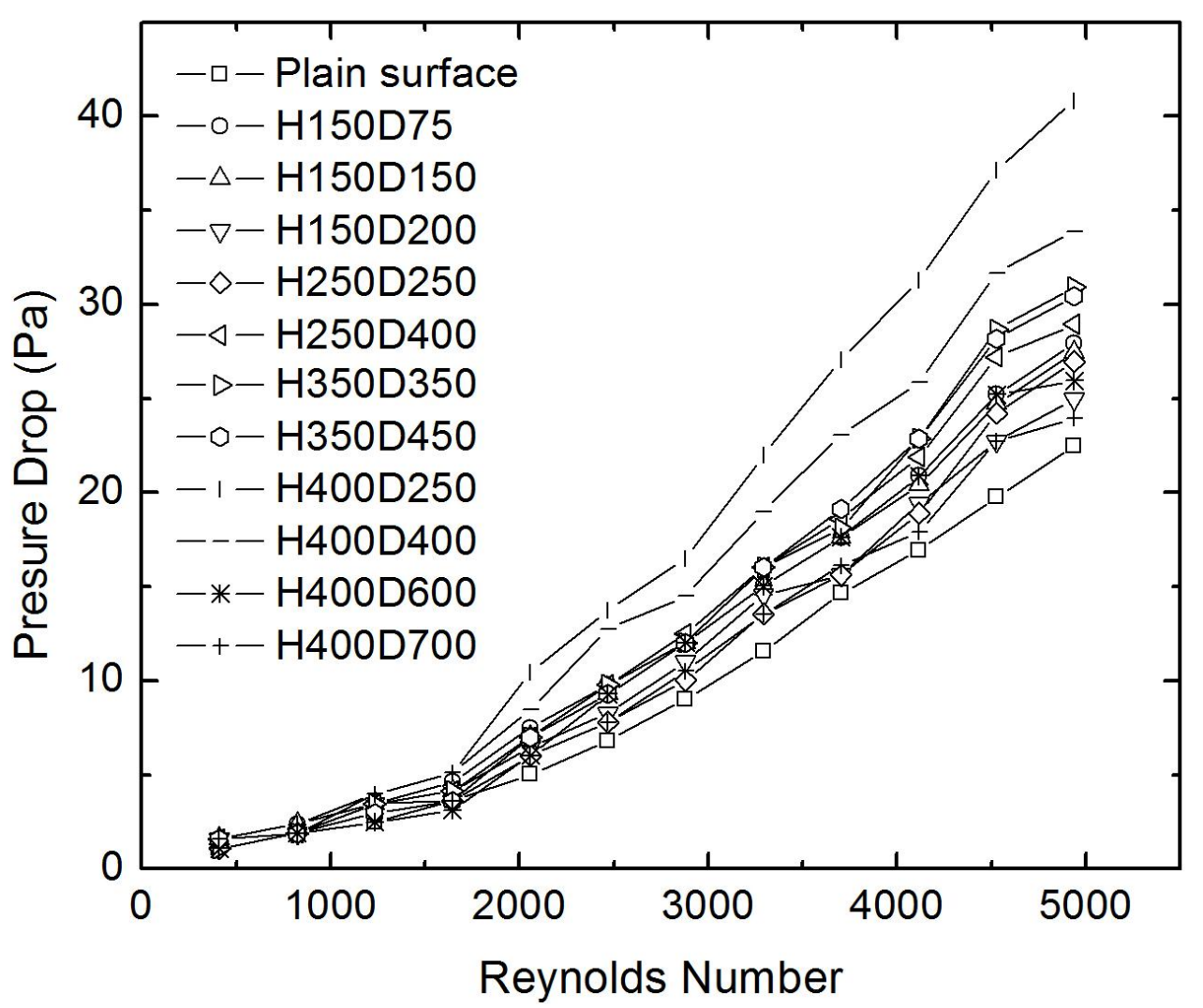

Fig. 9 Pressure drops over micro pin fin arrays at different Reynolds numbers

For each group, pressure drop tends to increase with decreasing pin fin diameter except for the group with a pin fin height of $250 \mu \mathrm{m}$. This might be related to area increases with micro pin fin arrays since a smaller pin fin diameter cases provide larger area increases for a fixed pin fin height and $S / D$ ratio, as shown in Table 1.

Figures 11 and 12 present friction factors corresponding to pressure drops of plain surfaces and of each micro pin fin array. Their results are compared with the well-known correlations of plain surfaces of different wall roughness values. For the correlation of the laminar flow regime, $f=75 / \operatorname{Re}[26]$, which is based on the aspect ratio of the rectangular channel of the current study. Correlations for the turbulent flow regime by Blasius and Haaland are [27]:

$$
f=0.316 \operatorname{Re}_{d}^{-1 / 4}, 4000<\operatorname{Re}_{d}<10^{5} \quad \text { (Blasius) }
$$




$$
f=1 / \sqrt{-1.8 \log \left[\frac{6.9}{R e_{d}}+\left(\frac{\varepsilon / d}{3.7}\right)^{1.11}\right]} \quad \text { (Haaland) }
$$

where $\varepsilon$ represents an equivalent roughness height of a micro pin fin.
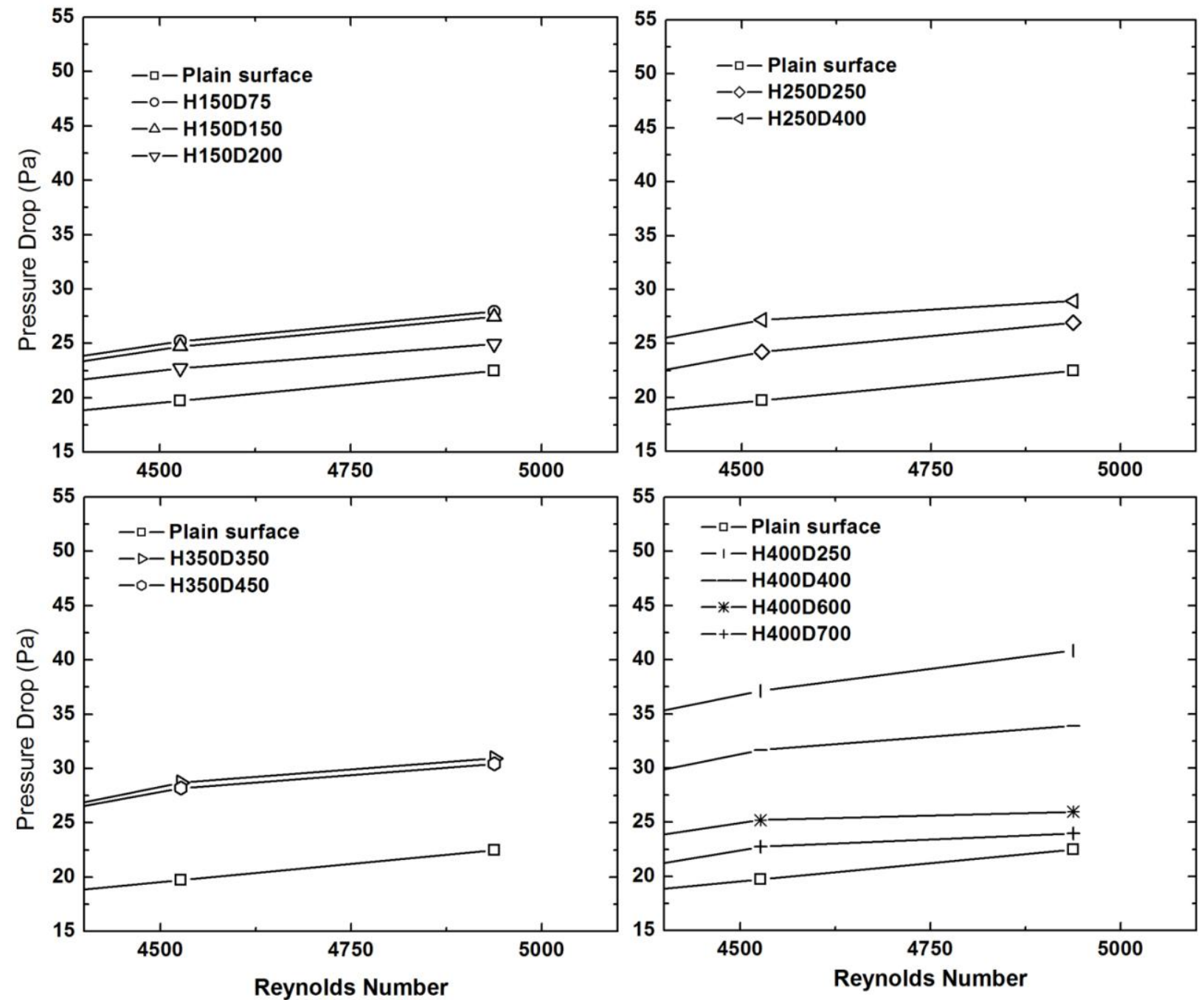

Fig. 10 Pressure drops over micro pin fin arrays at high Reynolds numbers of above 4000

Figure 11 shows that the experimental friction factors for lower Reynolds numbers, below 1000, seem to have small deviations from the plain surface correlation of $f=75 / \mathrm{Re}$. As Reynolds number increases the experimental data start to nicely follow the Blasius correlation and match well within the turbulent regime. In addition, a transition point in the friction factor slope is 
captured well from the experiment. This agrees with the correlations and is at Reynolds numbers of around 1500 .

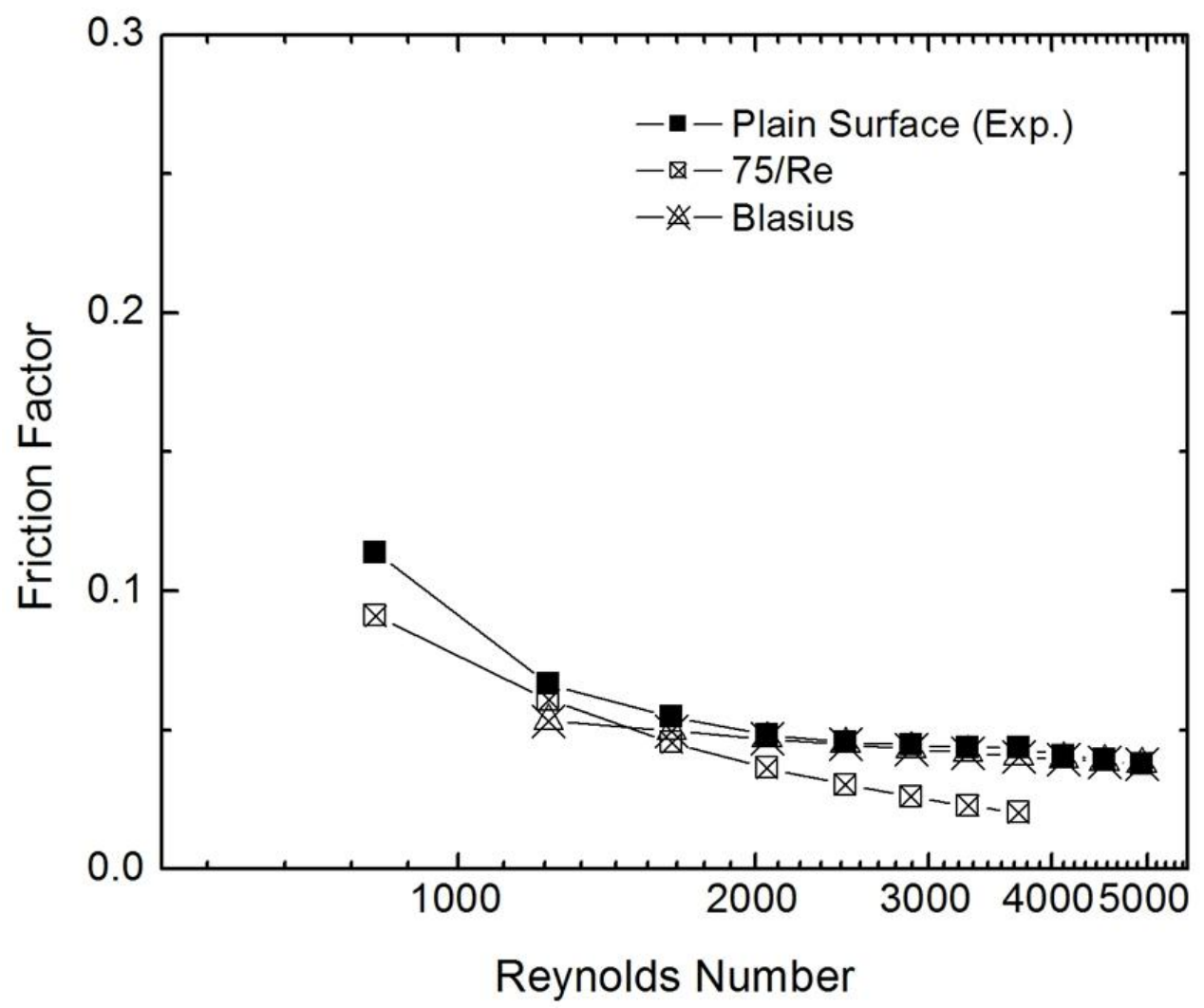

Fig. 11 Friction factors of plain surface at different Reynolds numbers

Figure 12 shows the friction factors of the plain surface and micro pin fin arrays. They are compared to the Haaland correlation for the turbulent flow regime. First of all, the plain surface case friction factors match well with the Haaland correlation for smooth walls at Reynolds number above 2000. The friction factors of the micro pin fin arrays are mostly shown to be higher than those of the plain surface, both in the laminar and turbulent flow regimes and seem to follow the trends of $\mathrm{f}=75 / \mathrm{Re}$ and the correlation of Blasius. The micro pin fin friction factors from the Haaland correlations are shown to be higher than the experimental values for all the pin fin or roughness height cases. Herein, it is noted that the test section channel of the present study has micro pin fins on only one side of the walls whereas the Haaland correlation assumes that all 
the walls of the channel are roughened. This could be one reason for the deviation between the experiment and the Haaland correlation shown in Figure 12.

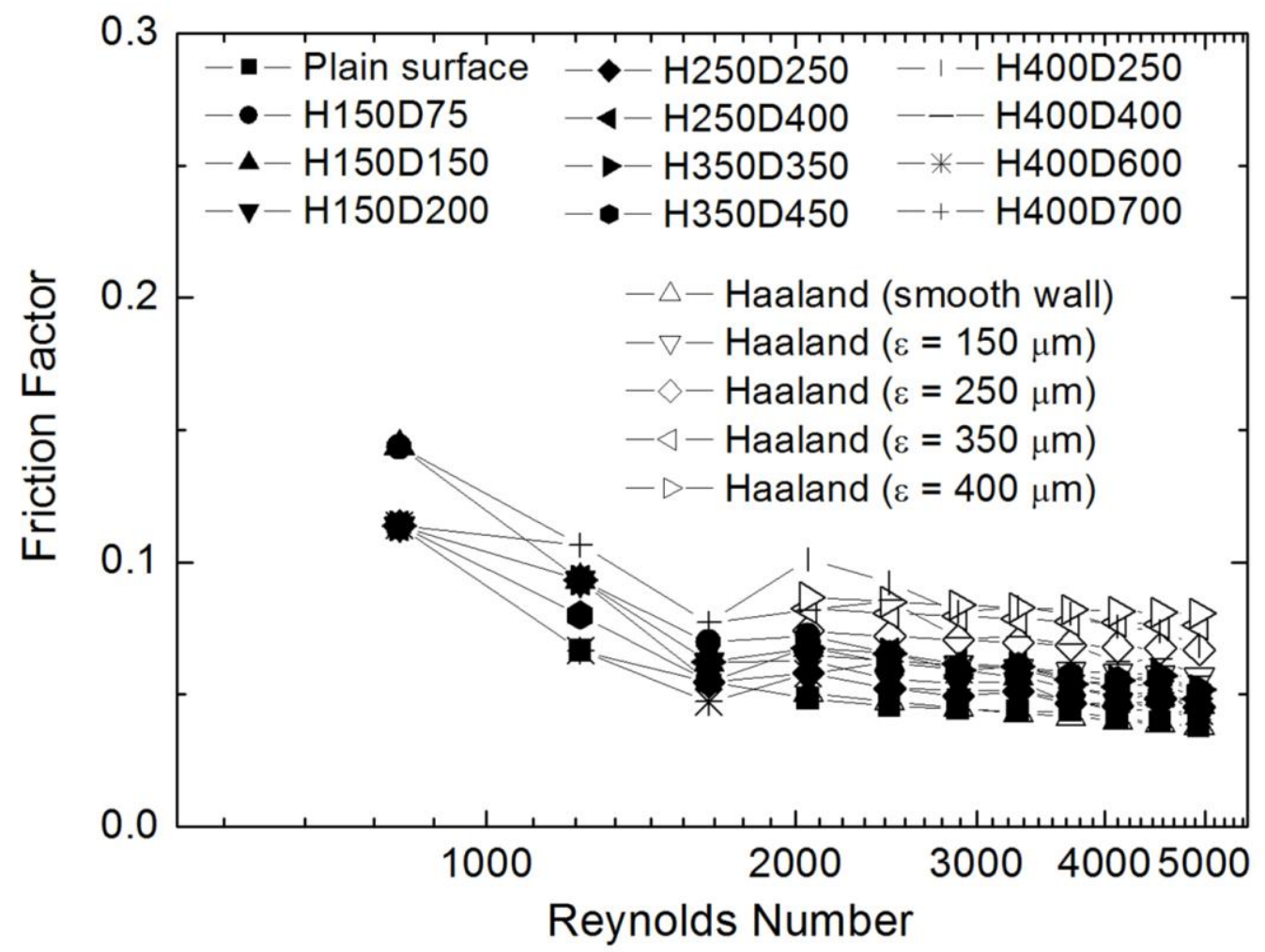

Fig. 12 Friction factors of micro pin fin arrays at different Reynolds numbers

Figure 13 shows more detailed friction factor comparisons over higher Reynolds number ranges.

The Haaland correlations with different wall roughness heights suggest that the friction factor is a function of pin fin height and is independent of pin fin diameter in the turbulent flow regime. However, this does not agree with the experimental results of Figure 13, as the H350D350 and H350D450 cases have the largest friction factors among the micro pin fin cases. In the patterned micro pin fin arrays, the diameter might also have a significant effect on friction factor. Further study is needed to better address this issue. 


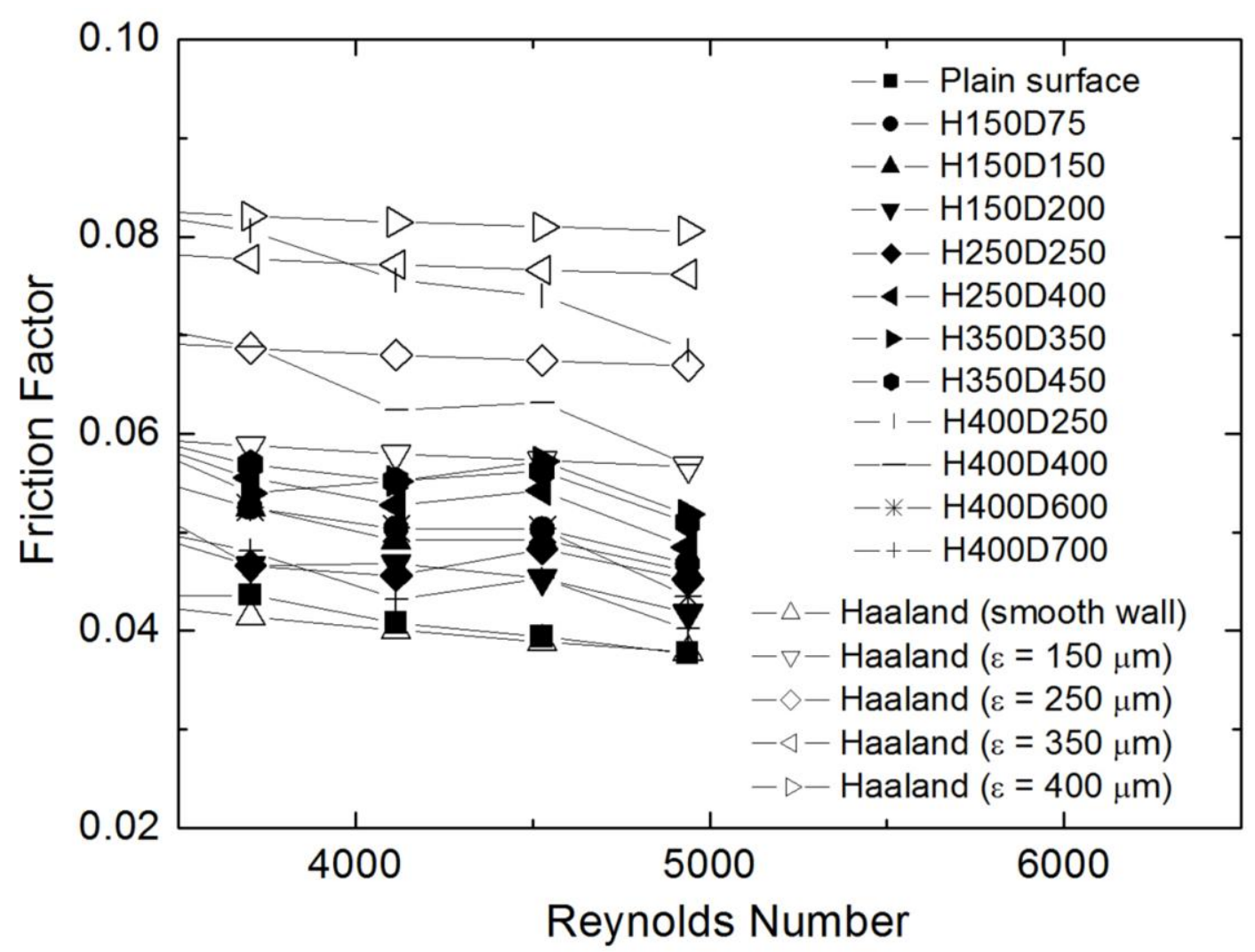

Fig. 13 Friction factors of micro pin fin arrays at higher Reynolds numbers

\subsection{Nusselt number and performance index}

Previous studies about micro pin fins presented correlations for Nusselt numbers [10, 11, 14, 28]. Most of these cases are for shrouded micro pin fins in channels that allow no clearance, or very small clearances, between the micro pin fin tips and the channel walls. Therefore, their conditions resemble the well-known problem of flow across a bank of cylinders. On the other hand, the micro pin fin arrays in the current study are positioned in the channel with large open spaces above the pin fin tips, ranging from around ten times to more than twenty times of pin fin heights. This open space allows the flow to bypass into this area rather than to go through the bank of micro pin fins. Therefore, it seems unreasonable to compare the results of the current study with the correlations for shrouded micro pin fins in the literature. Instead, we treat the 
micro pin fins as wall roughness elements in the channel, and thereby, the correlation by Norris [29] was used for Nusselt number estimation:

$$
\frac{N u}{N u_{\text {smooth }}}=\left(\frac{f}{f_{\text {smooth }}}\right)^{n}
$$

where $n=0.68 \operatorname{Pr}^{0.215}$. Figure 14 shows Nusselt numbers of each micro pin fin array compared to the Norris correlation with the friction factors calculated by the Haaland correlation for different micro pin fin heights.
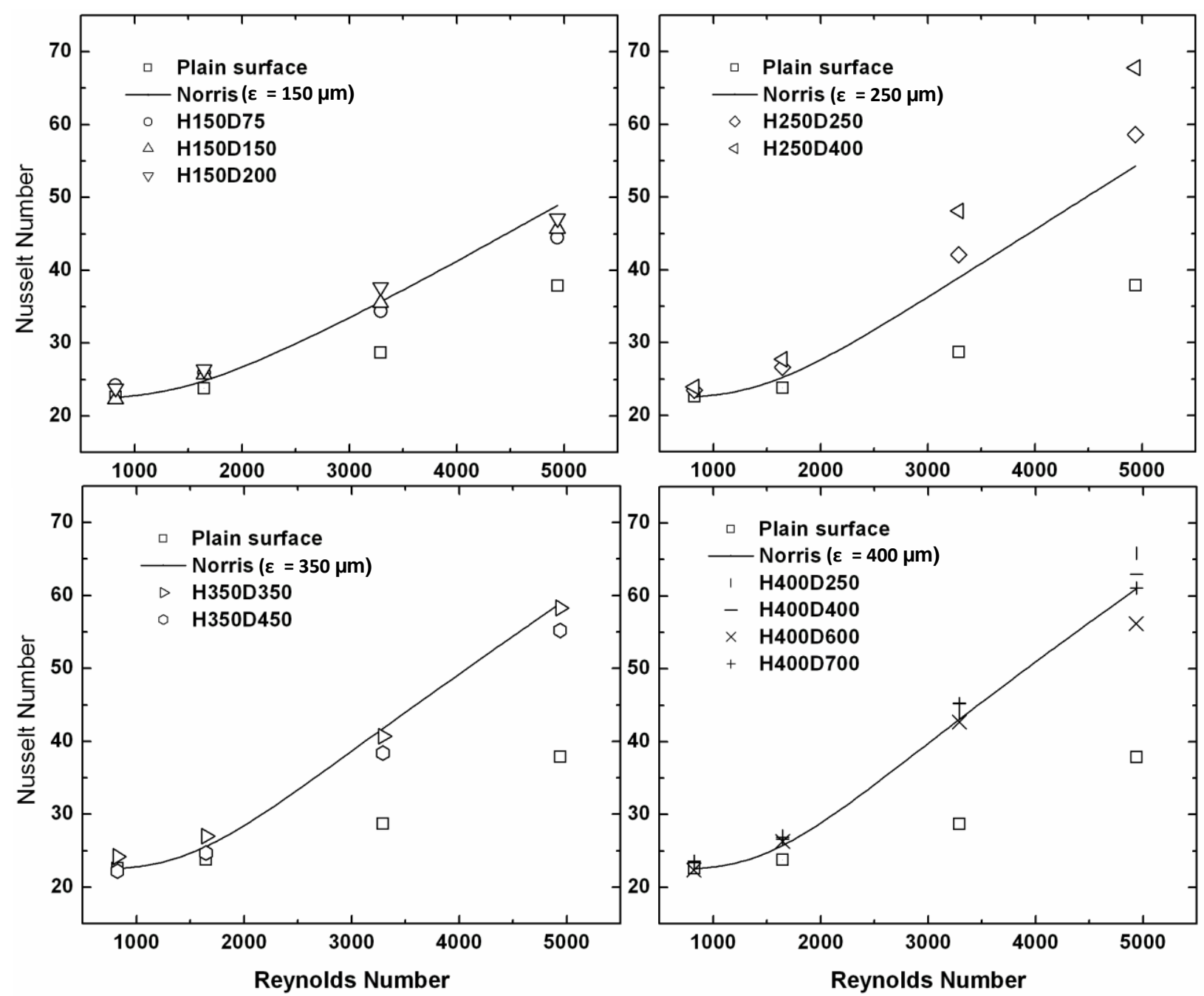

Fig. 14 Nusselt numbers of micro pin fins compared to the correlations at different micro pin fin heights 
The results from the correlations show that the higher micro pin fin arrays generate larger Nusselt numbers. This tendency corresponds to the experimental results, with a few exceptions. The case of H250D400 shows the largest Nusselt numbers among all the cases. This particular case might be the most desirable design of micro pin fin arrays among those in the current study. This design shows increased fluid dynamics activity and the highest heat transfer augmentation. The Nusselt numbers from the correlations agree well with experimental results. The deviation from the data become less significant with lower Reynolds numbers. Some literature introduced a thermal performance ratio to judge the performance of micro pin fins in terms of both pressure drop and heat transfer enhancement. Siw et al. [9], Marques and Kelly [11], and Prasher et al. [14] defined the performance ratio as:

$$
\eta=\frac{\left(N u / N u_{p}\right)}{\left(f / f_{p}\right)^{1 / 3}}
$$

where subscript $p$ represents the plane surface. The calculated performance ratio of the micro pin fin arrays with the above definition are shown in Figure 15. According to the results, the H250D400 case, which has the largest heat transfer coefficient, shows the best performance, considering both heat transfer and frictional aspects over the full range of flow rates. Moores and Joshi [10] used a slightly different definition of the performance ratio:

$$
\eta=\frac{\left(N u / N u_{p}\right)}{\left(f / f_{p}\right)}
$$

This equation places more emphasis on friction factors than does Equation (17). The performance ratio of the micro pin fin arrays for different flow rates based upon Equation (18) is presented in Figure 16. The H400D700 case shows the best performance for the higher flow rates of 40 LPM and 60 LPM. For the lower flow rates, all the cases seem to show similar performance. From the results of the two performance ratio analyses, cases H250D400 and 
H400D700 are shown to be the best configurations among the micro pin fin arrays of the present study. Both cases seem to have the highest fluid activity for augmenting heat transfer rate. It is noted that these two cases have the largest pin fin diameters in their groups and the diameter is the main factor for increasing fluid dynamics activity, as discussed previously. This also indicates that increasing fluid dynamics activity is more important than just increasing heat transfer area in enhancing performance of air-cooled heat sinks, considering both hydrodynamics and thermal aspects.

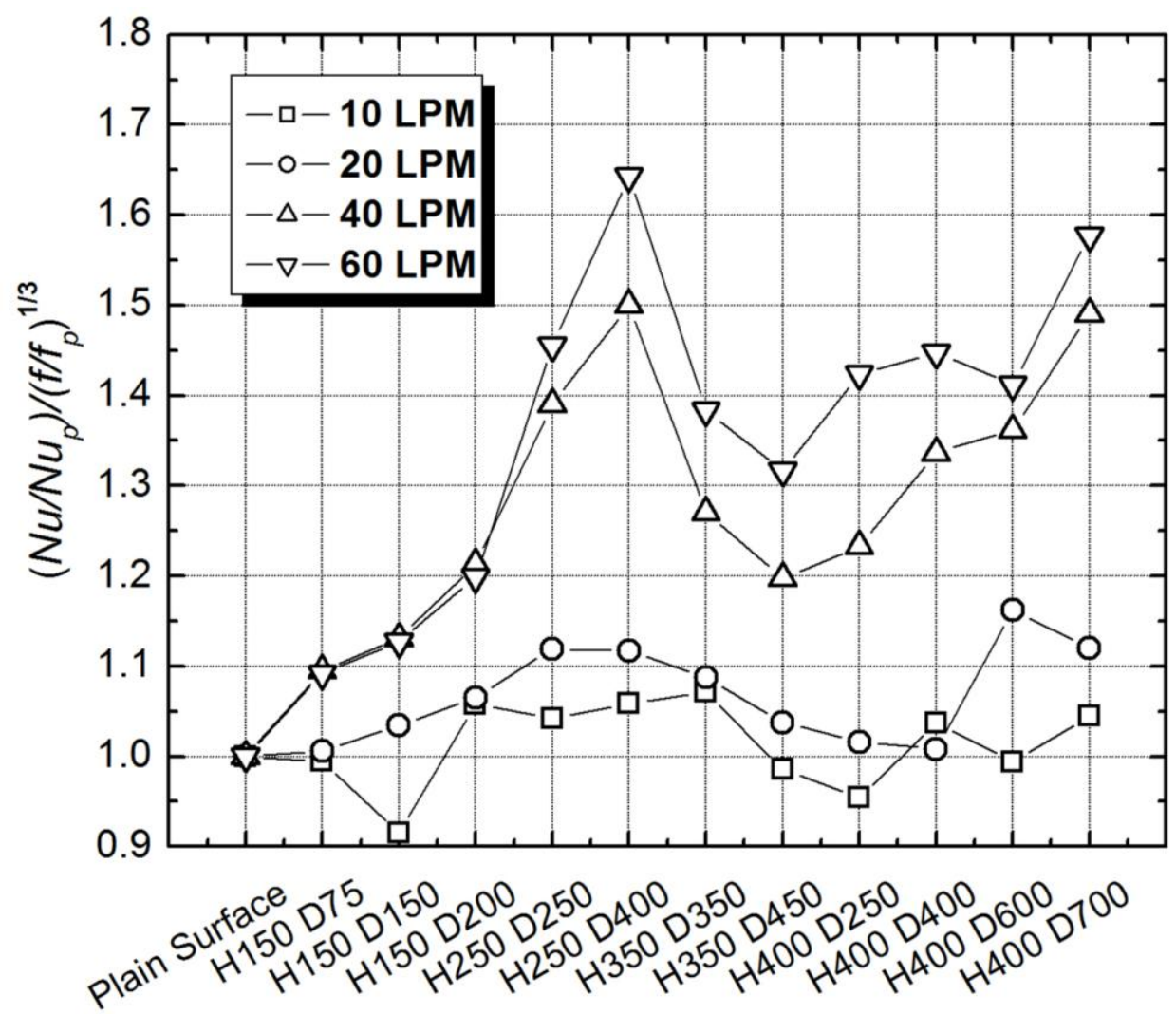

Fig. 15 Performance ratios of micro pin fin arrays based on Eqn. (17) 


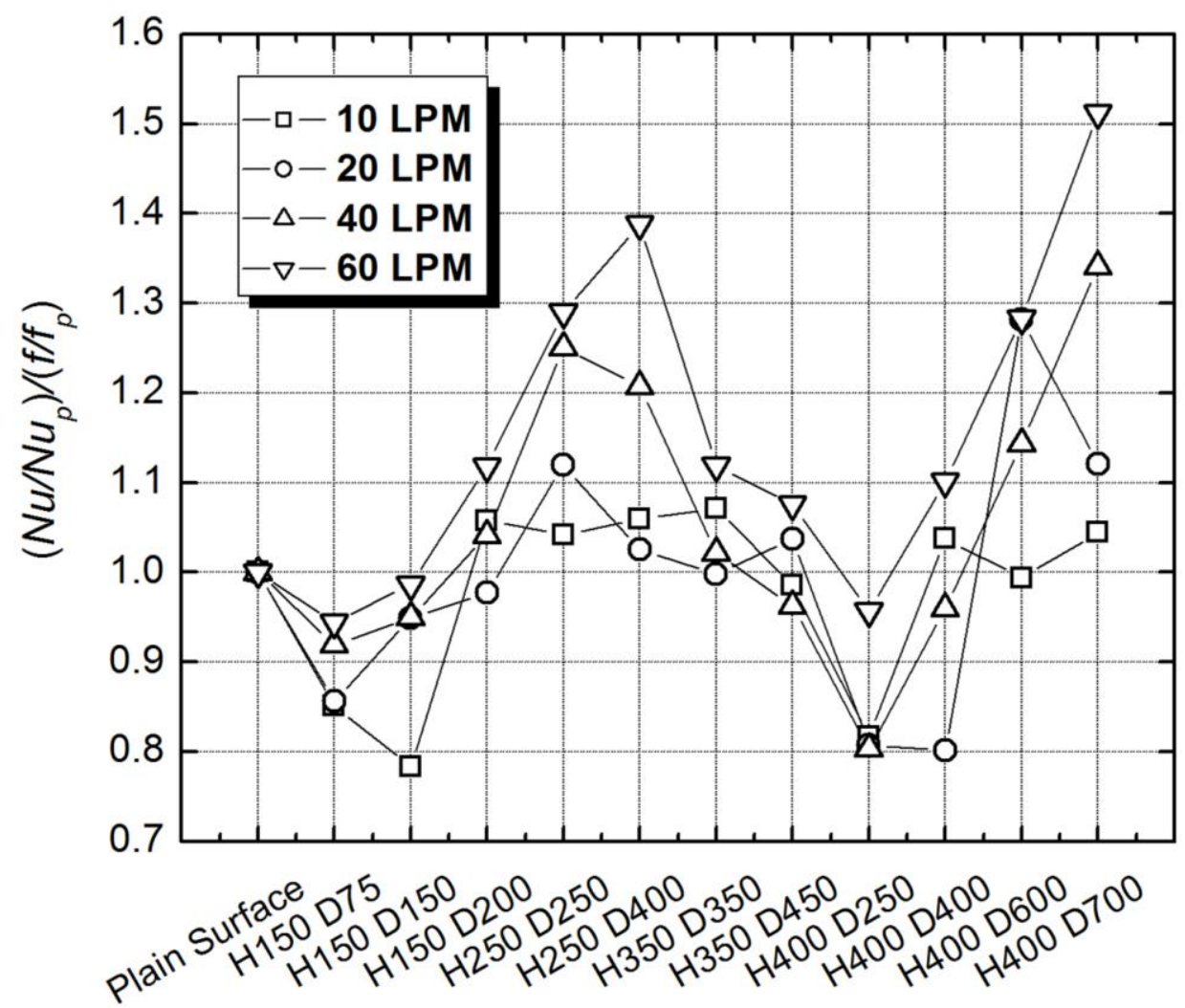

Fig. 16 Performance ratios of micro pin fin arrays based on Eqn. (18)

\section{Conclusions}

In this paper, heat transfer and pressure drop of micro pin fin arrays in a rectangular channel were studied experimentally. The copper micro pin fin arrays were fabricated on the copper substrate using the LIGA photolithography process. Heat transfer experiments were conducted with different channel through-flow rates of air. In the group with smaller micro pin fin heights of $150 \mu \mathrm{m}$ and $250 \mu \mathrm{m}$, the larger diameter geometries tend to provide higher heat transfer rates when the coefficients are calculated based on the base area. In the group with larger micro pin fin heights of $350 \mu \mathrm{m}$ and $400 \mu \mathrm{m}$, the effects of diameter on heat transfer become less important. The maximum heat transfer enhancement of $79 \%$ is achieved with the arrays of micro pin fins of $250 \mu \mathrm{m}$ length and $400 \mu \mathrm{m}$ diameter. The main contribution to the enhancement is in fluid dynamics effects, rather than with the area increases. The fluid dynamics effects enhance 
heat transfer performance more significant at higher Reynolds numbers. The H400D250 case, with the largest area increase of $103 \%$, shows the second highest heat transfer rate enhancement. A pattern was found regarding the heat transfer coefficients calculated based on the actual heat transfer area. Fluid dynamic effects for enhancing heat transfer become stronger with increasing pin fin diameter with a fixed fin height. Pressure drops tend to increase with decreasing pin fin diameter, since a smaller pin fin diameter provides a larger friction area at a fixed pin fin height and $S / D$ ratio. Nusselt numbers from experimental results are compared with the Norris correlations, showing good agreement. Performance ratio analyses suggest that the H250D400 and H400D700 cases are the best micro pin fin arrays of the current study in terms when both heat transfer and pressure drop are considered. Given the promising results provided in this work, the micro pin-fin surfaces can be used for enhancing heat transfer performance of conventional air-cooled heat sinks for electronics cooling. Future studies should include understanding the detailed mechanisms of fluid dynamic effects that play a main role in heat transfer improvement of micro pin-fin surfaces. That will help to obtain better optimized micro pin-fin surfaces under various cooling conditions.

\section{Acknowledgements}

This work was partially supported by the Defense Advanced Research Projects Agency (DARPA) MACE Program. The views expressed are those of the authors and do not reflect the official policy or position of the Department of Defense or the U.S. Government. Approved for Public Release, Distribution Unlimited. 


\section{Nomenclatures}

$A_{\text {actual }}=$ Actual increased convection area due to micro pin fins, $\mathrm{mm}^{2}$

$A_{\text {base }}=$ Base area of micro pin fin plate, $\mathrm{mm}^{2}$

$A_{c}=$ Cross sectional area of copper block, $\mathrm{mm}^{2}$

$D=$ Pin fin diameter, $\mathrm{mm}$

$d=$ Hydraulic diameter of channel, $\mathrm{mm}$

$f=$ Friction factor

$f_{\text {smooth }}=$ Friction factor of smooth surface

$f_{p}=$ Friction factor of plain copper surface

$H=$ Pin fin height, $\mathrm{mm}$

$K=$ Loss factor

$k=$ Thermal conductivity of copper, W/m K

$k_{p}=$ Thermal conductivity of thermal paste, $\mathrm{W} / \mathrm{m} \mathrm{K}$

$k_{f}=$ Thermal conductivity of air, W/m K

$L=$ Test section length, $\mathrm{mm}$

$l_{\text {sub }}=$ Distance between convection surface and temperature measuring point, $\mathrm{mm}$

$\mathrm{h}=$ Heat transfer coefficient, $\mathrm{W} / \mathrm{m}^{2} \mathrm{~K}$

$N_{m p}=$ Number of pin fins

$\mathrm{Nu}=$ Nusselt number

$N u_{p}=$ Nusselt number of plain copper surface

$P_{\text {static }}=$ Static pressure at the channel outlet, $\mathrm{Pa}$

$P r=$ Prandtl number

$q=$ Heat input, $\mathrm{W}$

$R e=$ Reynolds number

$R e_{d}=$ Reynolds number based on hydraulic diameter of the channel

$S=$ Pin fin pitch, $\mathrm{mm}$

$T_{\text {in }}=$ Channel inlet temperature, $\mathrm{K}$

$T_{\text {out }}=$ Channel outlet temperature, $\mathrm{K}$

$T_{s u b, i}=$ Temperature measured below the convection surface, $\mathrm{K}$

$T_{\text {sur }, i}=$ Extrapolated surface temperature, $\mathrm{K}$

$T_{\text {sur }}=$ Averaged surface temperature, $\mathrm{K}$

$\Delta T_{L M T D}=\log$ Mean Temperature difference, $\mathrm{K}$

$x=$ Gap distance at the interface between micro pin fin plate and copper block, $\mathrm{mm}$

$z=$ Manometer reading

Greek symbols

$\xi=$ Porosity of micro pin fin arrays

$\varepsilon=$ Relative surface roughness

$\rho_{\text {water }}=$ Density of water, $\mathrm{kg} / \mathrm{m}^{3}$

$\rho_{\text {air }}=$ Density of air, $\mathrm{kg} / \mathrm{m}^{3}$ 


\section{[References]}

[1] M.K. Chyu, Heat Transfer and Pressure Drop for Short Pin-Fin Arrays With Pin-Endwall Fillet, Journal of Heat Transfer, 112(4) (1990) 926-932.

[2] E.M. Sparrow, J.W. Ramsey, Heat transfer and pressure drop for a staggered wall-attached array of cylinders with tip clearance, International Journal of Heat and Mass Transfer, 21(11) (1978) 1369-1378.

[3] E.M. Sparrow, J.W. Ramsey, C.A.C. Altemani, Experiments on In-line Pin Fin Arrays and Performance Comparisons with Staggered Arrays, Journal of Heat Transfer, 102(1) (1980) 44-50. [4] D.E. Metzger, R.A. Berry, J.P. Bronson, Developing Heat Transfer in Rectangular Ducts With Staggered Arrays of Short Pin Fins, Journal of Heat Transfer, 104(4) (1982) 700-706.

[5] D.E. Metzger, C.S. Fan, S.W. Haley, Effects of Pin Shape and Array Orientation on Heat Transfer and Pressure Loss in Pin Fin Arrays, Journal of Engineering for Gas Turbines and Power, 106(1) (1984) 252-257.

[6] Y. Peng, Heat Transfer and Friction Loss Characteristics of Pin Fin Cooling Configurations, Journal of Engineering for Gas Turbines and Power, 106(1) (1984) 246-251.

[7] M.K. Chyu, Y.C. Hsing, V. Natarajan, Convective Heat Transfer of Cubic Fin Arrays in a Narrow Channel, Journal of Turbomachinery, 120(2) (1998) 362-367.

[8] Q. Li, Z. Chen, U. Flechtner, H.-J. Warnecke, Heat transfer and pressure drop characteristics in rectangular channels with elliptic pin fins, International Journal of Heat and Fluid Flow, 19(3) (1998) 245-250.

[9] S.C. Siw, M.K. Chyu, T.I.P. Shih, M.A. Alvin, Effects of Pin Detached Space on Heat Transfer and Pin Fin Arrays, Journal of Heat Transfer, 134(8) 2012 491-500.

[10] K.A. Moores, Y.K. Joshi, Effect of Tip Clearance on the Thermal and Hydrodynamic Performance of a Shrouded Pin Fin Array, Journal of Heat Transfer, 125(6) (2003) 999-1006.

[11] C. Marques, K.W. Kelly, Fabrication and Performance of a Pin Fin Micro Heat Exchanger, Journal of Heat Transfer, 126(3) (2004) 434-444.

[12] A. Koşar, C. Mishra, Y. Peles, Laminar Flow Across a Bank of Low Aspect Ratio Micro Pin Fins, Journal of Fluids Engineering, 127(3) (2005) 419-430.

[13] Y. Peles, A. Koşar, C. Mishra, C.-J. Kuo, B. Schneider, Forced convective heat transfer across a pin fin micro heat sink, International Journal of Heat and Mass Transfer, 48(17) (2005) 3615-3627.

[14] R.S. Prasher, J. Dirner, J.-Y. Chang, A. Myers, D. Chau, D. He, S. Prstic, Nusselt Number and Friction Factor of Staggered Arrays of Low Aspect Ratio Micropin-Fins Under Cross Flow for Water as Fluid, Journal of Heat Transfer, 129(2) (2007) 141-153.

[15] C. Wang, Y. Youmin, T.W. Simon, C. Tianhong, M.T. North, Microfabrication of Short Pin Fins on Heat Sink Surfaces to Augment Heat Transfer Performance, in: Thermal and Thermomechanical Phenomena in Electronic Systems (ITHERM), 13th IEEE Intersociety Conference on, 2012, pp. 944-950.

[16] E. Galvis, B.A. Jubran, F. Xi, K. Behdinan, Z. Fawaz, Numerical Modeling of Pin-Fin Micro Heat Exchangers, Heat and Mass Transfer, 44(6) (2008) 659-666.

[17] J. F. Tullius, T. K. Tullius, Y. Bayazitoglu, Optimization of Short Micro Pin Fins in Minichannels, International Journal of Heat and Mass Transfer, 55(15-16) (2012) 3921-3932.

[18] O. O. Adewumi, T. Bello-Ochende, J.P. Meyer, Constructal Design of Combined Microchannel and Micro Pin Fins for Electronic Cooling, International Journal of Heat and Mass Transfer, 66 (2013) 315-323. 
[19] G. L. Wang, D. W. Yang, Y. Wang, D. Niu, X. L. Zhao, G. F. Ding, Heat Transfer and Friction Characteristics of the Microfluidic Heat Sink with Variously-Shaped Ribs for Chip Cooling, Sensors, 15(4) (2015) 9547-9562.

[20] Z. Wan, Y. Joshi, Pressure Drop and Heat Transfer Characteristics of Square Pin Fin Enhanced Microgaps in Single Phase Microfluidic Cooling, in: Thermal and Thermomechanical Phenomena in Electronic Systems (ITHERM), 14th IEEE Intersociety Conference on, 2014, pp. 649-657.

[21] T. Yeom, T.W. Simon, T. Zhang, M.T. North, T. Cui, Convective Heat Transfer Enhancement with Micro Pin-Fin Surfaces Cooled by a Piezoelectrically-Driven Translational Agitator, in: ASME International Mechanical Engineering Congress and Exposition, Houston, Texas, USA, 2012, pp. 685-691.

[22] T. Yeom, T.W. Simon, Y. Yu, M. Zhang, S. Agrawal, L. Huang, T. Zhang, M.T. North, T. Cui, An Active Heat Sink System with Piezoelectric Translational Agitators and Micro Pin Fin Arrays, in: ASME International Mechanical Engineering Congress and Exposition, Houston, Texas, USA, 2012, pp. 1479-1488.

[23] T. Yeom, T.W. Simon, M. Zhang, M.T. North, T. Cui, High frequency, large displacement, and low power consumption piezoelectric translational actuator based on an oval loop shell, Sensors and Actuators A: Physical, 176(0) (2012) 99-109.

[24] R.S. Prasher, J. Dirner, J.-Y. Chang, A. Myers, D. Chau, D. He, S. Prstic, Thermal Resistance and Pressure Drop of Silicon Based Micro Pin Fin Heat Exchanger Under Cross Flow in: ASME Pacific Rim Technical Conference and Exhibition on Integration and Packaging of MEMS, NEMS, and Electronic Systems, San Francisco, California, USA, 2005, pp. 717-725.

[25] A. Koşar, Y. Peles, Convective flow of refrigerant (R-123) across a bank of micro pin fins, International Journal of Heat and Mass Transfer, 49(17-18) (2006) 3142-3155.

[26] F.M. White, Viscous Fluid Flow, Third ed., McGraw. Hill.

[27] F.M. White, Fluid Mechanics, Sixth ed., McGraw. Hill.

[28] M. Liu, D. Liu, S. Xu, Y. Chen, Experimental study on liquid flow and heat transfer in micro square pin fin heat sink, International Journal of Heat and Mass Transfer, 54(25-26) (2011) 5602-5611.

[29] W. Kays, M. Crawford, B. Weigand, Convective Heat and Mass Transfer, Fourth ed. 


\section{Figure Captions}

Fig. 1 The diagrams of heat transfer experiment facility

Fig. 2 Test section of the heat transfer experiment

Fig. 3 Configurations of the channel and micro pin fins

Fig. 4 Fabrication process of the copper micro pin fin plate, (a) Ti metal layer deposition, (b)

KMPR photoresist mold development, (c) Ti layer etching, (d) Copper pin fin electroplating, (e)

KMPR photoresist removal, (f) SEM image of micro pin fin arrays

Fig. 5 Heat transfer coefficient comparisons of micro pin fin arrays with the height of $150 \mu \mathrm{m}$ and different fin diameters

Fig. 6 Heat transfer coefficient comparisons of micro pin fin arrays with the height of $250 \mu \mathrm{m}$ and different fin diameters

Fig. 7 Heat transfer coefficient comparisons of micro pin fin arrays with the height of $350 \mu \mathrm{m}$ and different fin diameters

Fig. 8 Heat transfer coefficient comparisons of micro pin fin arrays with the height of $400 \mu \mathrm{m}$ and different fin diameters

Fig. 9 Pressure drops over micro pin fin arrays at different Reynolds numbers

Fig. 10 Pressure drops over micro pin fin arrays at high Reynolds numbers of above 4000

Fig. 11 Friction factors of plain surface at different Reynolds numbers

Fig. 12 Friction factors of micro pin fin arrays at different Reynolds numbers

Fig. 13 Friction factors of micro pin fin arrays at higher Reynolds numbers

Fig. 14 Nusselt numbers of micro pin fins compared to the correlations at different micro pin fin heights

Fig. 15 Performance ratios of micro pin fin arrays based on Eqn. (17)

Fig. 16 Performance ratios of micro pin fin arrays based on Eqn. (18) 